NBER WORKING PAPER SERIES

\title{
MORTALITY, INCOME, AND INCOME INEQUALITY OVER TIME IN BRITAIN AND THE UNITED STATES
}

\author{
Angus Deaton \\ Christina Paxson \\ Working Paper 8534 \\ http://www.nber.org/papers/w8534
NATIONAL BUREAU OF ECONOMIC RESEARCH
1050 Massachusetts Avenue
Cambridge, MA 02138 \\ October 2001
}

Prepared for the NBER conference on aging, The Boulders, Carefree, Arizona, May 17-20, 2001. We are grateful to the National Institute on Aging for its support through the NBER, and to the John D. and Catherine T. MacArthur Foundation for support for its network on inequality and poverty in broader perspectives. We thank Thu Vu for research assistance and Sir George Alleyne, James Banks, Anne Case, David Cutler, Victor Fuchs, Joe Newhouse, and Jim Smith for comments and suggestions. The views expressed herein are those of the authors and not necessarily those of the National Bureau of Economic Research.

(C) 2001 by Angus Deaton and Christina Paxson. All rights reserved. Short sections of text, not to exceed two paragraphs, may be quoted without explicit permission provided that full credit, including $\mathbb{C}$ notice, is given to the source. 
Mortality, Income, and Income Inequality Over Time in Britain and the United States Angus Deaton and Christina Paxson

NBER Working Paper No. 8534

October 2001

JEL No. I12

\begin{abstract}
$\underline{\text { ABSTRACT }}$
We investigate age-specific mortality in Britain and the United States since 1950. Neither trends in income nor in income inequality provide plausible explanations. Britain and the US had different patterns of income growth but similar patterns of mortality decline. Patterns of income inequality were similar in both countries, but adult and elderly mortality rates declined most rapidly during the period when inequality increased. Changes in the rate of mortality decline in the US led changes in Britain by about four years, most notably for infant and older adult mortality where there have been significant technical improvements in treatment. British mortality is lower, but the schedules cross at around age 65 . This pattern was established before Medicare, and most likely comes from rationing by age in Britain. Merged income, income inequality, and mortality data on an age/year (or cohort/year) basis show no evidence that income has any effect on mortality in Britain. Education is protective, but less so than in the US. Understanding the effect of income on mortality presents many puzzles, between countries, and between analyses at different levels of aggregation. Our results suggest an important role for medical technology in determining the rate of mortality decline since 1950.
\end{abstract}

Angus Deaton

Center for Health and Wellbeing

347 Wallace Hall

Princeton University

Princeton, NJ 08544

and NBER

Tel: 609-258-5967

Fax: 609-258-5974

deaton@princeton.edu
Christina Paxson

Center for Health and Wellbeing

316 Wallace Hall

Princeton University

Princeton, NJ 08544

and NBER

Tel: 609-258-6474

Fax: 609-258-5974

cpaxson@princeton.edu 


\section{Introduction}

This paper is concerned with the time-series patterns of mortality, income, and income inequality in the United States and in Britain. One starting point is Deaton and Paxson (2001), in which we used pooled time-series and cross-sectional data from the US to estimate a strong protective effect of income across birth cohorts that closely matched estimates from individual-level data from the National Longitudinal Mortality Study. We found no evidence for the proposition that year and age-specific income inequality is a health hazard; indeed, our regressions found protective effects of higher inequality, essentially because for adults aged 35 and over in the US, mortality declined more rapidly during the period of rapid increase in income inequality in the 1980s than it did in the 1970s, before income inequality began to increase.

In this paper, we extend our analysis to British data, and to a comparative examination of the British and American mortality experience, over time, and across age groups. The comparison between the two countries is interesting in part because of the different systems of health care, one country with universal, albeit often rationed, coverage, and the other with largely private provision until Medicare at age 65. Comparative analysis is also useful because there are both similarities and differences in patterns of income in the two countries. Although changes in income inequality are similar in Britain and the US, patterns of income growth are not. According to purchasing power parity estimates, incomes are higher in the US than in Britain, but, in recent years, real incomes have been growing more rapidly in Britain. Both countries experienced historically large increases in income inequality in the 1980s. 
Section 2 presents an examination of the patterns of income, income inequality and mortality in the two countries over the last half century. Section 3 is concerned with a age-specific and time-series analysis of mortality and income in Britain, and with the comparison of the results with those from the US.

\section{Patterns of mortality in Britain and the US since 1950}

We begin our discussion with an examination of changes in mortality in the US and in Britain over the period 1950 to 2000, particularly in relation to changes in income and income inequality. In this section, we rely entirely on graphical analysis. Figure 1 shows the data on income and income inequality. The top panels show measures of real income in the two countries, and the bottom panels measures of income inequality. The two panels on the left are for the UK, and the two panels on the right are for the US. The top left panel shows two indicators of real income, both taken from the UK National Statistics website (http://www.statistics.gov.uk/). The lower curve shows real personal disposable income in pounds per capita at 1999 prices; this series is taken from the national income and product accounts. The upper curve, available for a shorter time period, and calculated from survey data, shows median household disposable income. Apart from the different methodologies, and the fact that households typically contain more than one person, the two series show similar business cycle and trend behavior over the period when both are available.

Data on income inequality are more controversial than data on income levels. There are many different estimates of the gini coefficient of income inequality in the UK, differing by concept and by source. The earlier gini coefficient shown in the bottom left panel, gini (a), comes from 
Deininger and Squire (1995). This series is identical to that reported in Goodman and Webb (1993) and Gottschalk and Smeeding (1997), and is one of the several series reported in Brandolini (1998) and Atkinson and Brandolini (2001). We also show a more recent series, gini (b), produced by the Institute for Fiscal Studies in London, and supplied to us by James Banks, see http://www.ifs.org.uk/election/ebn4.pdf. (A range of gini coefficients for the UK is given by Brandolini (1998). Although the series differ among themselves and with the gini coefficients shown in Figure 1, the pattern we are about to describe is consistent with the full range of data.) Income inequality in Britain changed relatively little until the early 1970s, though there is some evidence of a narrowing of inequalities during the Second World War. During the 1970s, income inequality seems to have declined, after which, from about 1978, there was a rapid increase. By about 1985 , the decline of the early 70 s had been undone, and the rate of growth of income inequality accelerated. Depending on the time frame, it is therefore possible to date the beginning of the increase from either the late 70s, or from the mid 1980s. By 1990, the increase appears to have stopped, and income inequality did not increase during the 1990s, remaining at the high level established by 1990 .

Given the lack of movement in income inequality in Britain until the 1970s, we can safely suppose that median incomes tracked mean incomes before the early 1970s. We can therefore conclude from the top left panel that median real income growth was somewhat faster after the early 1970s than before it. As we shall see, this is in sharp contrast to what happened in the United States, and this lack of any slowdown in British income growth will play an important role in our interpretation of the mortality data. 
The right-hand panels of Figure 1 show the income and income inequality data for the United States. On the top panel we present the US Census Bureau's estimate of real median family income, in 1999 dollars. The Census Bureau also publishes official estimates of the gini coefficient based on (partly unpublished) survey data from the Current Population Survey. These numbers, for both families and households (which can contain unrelated individuals) are shown in the lower left-hand panel. Both series have discontinuities between 1992 and 1993. The Census Bureau changed its questionnaires between those years, allowing a higher top value of income to be reported, and is unable to estimate how much of the change between 1992 and 1993 is real, see Jones and Weinberg (2000).

The experience of income inequality in the US is remarkably similar to that in the UK. Until the mid-1970s, there is little perceptible trend, though perhaps some narrowing. After 1972, income inequality increases, with the rate of increase accelerating in the mid-1980s. If we were to extrapolate across the breaks in the series, the increase goes on into the 1990s. However, it is also possible that the two detached arms should be lowered on to the earlier series, in which case, as in Britain, there is little or no increase in income inequality in the 1990s. In any case, there is no increase except across the disputed years 1992 and 1993.

Median incomes behave as the mirror image of income inequality. Prior to 1972, there was steady growth in real family incomes, and inequality, though varying from year to year, showed no trend. After 1972, the situation was reversed, with little growth in real median family incomes, and a rapid growth in income inequality. In the 1990s, and especially if we discount the apparent increase in income inequality, the earlier pattern appears to have resumed, with real growth in incomes and stable income inequality, albeit at a higher level than in the 1950s and 1960s. 
The different patterns of income growth in the two countries, and the similar patterns of income inequality, provide a useful background within which to examine how long term patterns of income and inequality growth have conditioned changes in mortality.

Figure 2 turns to the mortality data, beginning with infant mortality rates. Mortality data for England and Wales are available from 1851 to 1998 and come from the UK's Government Actuaries Department, see http://www.gad.gov.uk/b2/b2div6.htm\#life for information about obtaining the data. For infant mortality, we have merged in more recent data from the National Statistics website. Mortality data for the US are taken from the Berkeley Mortality Database at http://www.demog.berkeley.edu/wilmoth/mortality/.

Although infant mortality is not our main concern here, it is a useful starting point, because of its place in the previous literature, because it is likely to respond more rapidly than adult mortality to changes in the environment including any effects of income and income inequality, and because it will illustrate several of the themes that will recur in the discussion of mortality among adults and the elderly. In his 1996 book, Unhealthy Societies, Richard Wilkinson implicates the rise of income inequality in Britain in infant mortality, arguing that mortality rates fell less rapidly after 1985 than would have been the case had income inequality remained constant. Figure 5.10 of Wilkinson (1996, page 97) plots a time series of mortality, not only of infants, but also of children and young adults, and shows that the sum of age-adjusted mortality rates fell less rapidly after 1985 than it did in the decade from 1975 to 1985 . A good deal of the effect comes from changes in infant mortality, and the top panel of Figure 2 replicates Wilkinson's analysis using the log odds of mortality. We fit a regression line to the data from 1975 to 1985 , and plot the predicted values together with the full series from 1950 to 1999. After 1985, when income inequality was 
increasing in earnest, the infant mortality rate was indeed above the 1975 to 1985 trend. Note however that 1975 to 1985 saw the most rapid decrease in the post war period, and that the decline was also relatively slow, not only after 1985 , but also prior to 1975 , when income inequality showed no upward trend. Note also that there has been no resumption of the more rapid downward trend in the years after 1990 when inequality stopped increasing, indeed rather the reverse. So the case against income inequality is less than overwhelming, although it is true that the ten-year trend in infant mortality decline in Britain was broken around 1985, at the time that income inequality began to rise most rapidly.

A similar analysis for the US is shown in the bottom panel of Figure 2. The graphs for the two countries show marked similarities, with two periods of relatively slow decline bracketing a period of more rapid decline. In the US, the period of rapid decline is earlier than in the UK and lasts rather longer; it starts about 1965 and ends around 1980. Once again, the second period of slower decline (although not the first) coincides with the period of rapid inequality increase. And once again, there is no inequality episode to match the earlier period of slow decline, nor are there any signs of a return to more rapid progress after inequality stopped growing.

If we take the two countries together, there is no obvious link between infant mortality and the long-term growth in incomes. The pre- and post-1972 histories of real income are quite different in the two countries yet their mortality experiences are similar, albeit with some differences in timing. Furthermore, the rapid mortality decline in the US from 1965 to 1980 continued unabated notwithstanding the halt in the growth of real median family income after 1972. Instead, the most obvious feature of the two graphs is their similarity, especially if the British data are matched against lags of the American data. Indeed, if the British series is 
regressed on the contemporaneous and four lagged values of the American series, only the fourth lag is significantly different from zero, and it attracts a coefficient of 0.98 . A regression of British infant mortality on the fourth lag of American mortality, with a coefficient of unity, cannot be rejected against the alternative with current American mortality and all four lags. Such evidence is suggestive, not of any simple link between mortality, income, and income inequality, but rather of the importance of technological change, with technological innovations first appearing in the US and reaching Britain with about a four year lag.

Figure 3 shows plots of the log odds of mortality for England and Wales by 5 year age groups from 20-24 to 65-69. Females are shown on the left and males on the right, both drawn on the same scale. The top panels are for the younger groups, from 20-24 through to 40-44, and the bottom panels for the age groups from 45-49 through to 65-69. The mortality experience among those aged 70 and above is not shown here (but see Figure 6); its behavior over time is similar to the mortality rates of those aged 65 to 69 . It is important to look at younger and older groups separately, and also at males and females separately, because mortality of the four groups behaves quite differently. This differentiation by age is also an important reason for differentiating income and income inequality by age, which is one of the main motivations for our work on cohorts in section 3 .

Men always have higher mortality rates than women in the same age group. This is particularly true for young men under 30 . However, the most important difference between the younger and older groups, between the top and bottom panels, is in the behavior of their mortality rates over time. The younger groups, like infants in Figure 2, have more rapid mortality decline in the early years, before 1970, and much less rapid mortality declines — and in some cases (young 
men and the youngest women) even mortality increases - in the later years. The story is quite different for age groups over 40. There is a steady decline in mortality throughout the period, and the trend accelerates after the early 1970s. The acceleration in mortality decline is more pronounced for older and middle-aged men than for women, and more rapid among middle-aged than older women. The transition from the "young" pattern of deceleration to the "older" pattern of acceleration takes place gradually over age groups. In males aged from 35 to 44, for example, we see evidence of both patterns, with the acceleration setting in and then being reversed at the end of the period.

Whatever is the cause of these patterns, income inequality is an unlikely candidate, unless there is some ex ante reason to suppose that the young are more affected than the middle-aged and the elderly. Otherwise, the pattern of mortality and income inequality is wrong for those over 40 , just as it is right for the younger groups and for the infant mortality rate. Deaths from AIDS account for almost all of the increase in mortality rates among young men and of the elimination of mortality decline among the youngest groups of women. It is unclear that the AIDS epidemic would have been very different had there been no increase in income inequality.

Figure 4 shows mortality rates by age for men and women in the United States, using the same format as in Figure 3. As was the case with the infant mortality rates, there are marked similarities between the British and American experiences, though once again there are important differences in timing. The elimination of the decline in mortality rates among younger age groups, and its subsequent reversal, are more pronounced in the American data. Rising mortality rates among the youngest groups are more common, and are apparent even in the 40-44 age group of men. In the older groups, we see the same acceleration in mortality decline as in Britain. As 
before, it is more pronounced among men than among women, and more apparent for middleaged women than for those aged over 60 .

Because the pattern of income inequality in the US is so similar to that in Britain, income inequality is no more likely a cause of the American patterns than it is of the British ones. The American data also help us cast a good deal of doubt on the hypothesis that income is the main driving force behind mortality decline. The productivity slowdown in the US, and its associated decline in the rate of growth of real median incomes, is almost coincident with the acceleration in mortality decline among the middle-aged and elderly. Although it is undoubtedly possible to muddy the waters by thinking about income operating at a lag, perhaps of many years, any simple story is precluded by the fact that the histories of income growth and mortality decline both break into two prolonged and sharply different periods, and that the associations over these two periods are precisely the wrong way round.

If the mortality patterns are not driven by income and income inequality, what are their causes? There are many competing explanations. The differences between men and women may have something to do with their different histories of smoking, with women taking up the habit later than men, and with the long lags between smoking and its health consequences in heart disease and lung cancer. There was a worldwide decrease in coronary heart disease from the early 1970s, which one line of thought takes as evidence for the (co-)involvement of an infectious agent (chlamydia pneumoniae); for reviews and evidence against see Wald et. al. 2000 and Danesh et.al. 2000. The decline may instead have been due to major technical improvements in the treatment of heart disease, particularly the spread of angioplasty and of coronary by-pass grafts, as well as the increased use of drugs including aspirin and clot-busters. 
The role of medical technology in mortality decline is clarified by direct comparison of the British and American experiences. These are provided in Figure 5 for infant mortality and for middle-aged adults, and for the elderly in Figure 6. As always, we disaggregate by sex, and here show selected five year age groups. With the exception of 1950 and 1951 for infant mortality, American mortality rates are higher than British mortality rates up to age 65. For the elderly, mortality rates are higher in the UK. Aside from their levels, and as was the case for infant mortality, the development of mortality rates over time is similar in the two countries, though once again developments in the US—particularly the acceleration in mortality decline around 1970, and its more recent slowing — appear to lead the same developments in Britain. This evidence further serves to strengthen the supposition that variations in the rate of decline in these mortality rates is driven, not by income or income inequality, but by technological change, much of which is first implemented in the US and is subsequently transmitted to Britain. For the middleaged groups, from ages 45 through to 60 , and for both men and women, we replicate the result that we found for infant mortality, that in a regression of British on contemporaneous and four lags of American mortality rates, the fourth lag has a coefficient close to unity, while the contemporaneous and earlier lags are insignificantly different from zero.

Although it appears to benefit from technical progress first, the US has higher levels of mortality than Britain. One obvious explanation is the more or less universal access to health care in Britain than in the US, a hypothesis that might seem to be further supported by the cross-over after age 65, at which point most Americans are covered by Medicare. According to this story, the elderly in the US have the best of both worlds, with both good access and superior technology. The superior technology in the US benefits younger Americans less because of limited 
access. While there may be some truth in this account, it faces two immediate problems. First, the difference between British and American mortality rates is steadily diminishing with age. Although the cross-over takes place around age 65, the graphs for those aged 55 to 59 are closer than those aged from 45 to 49. Similarly, after the crossover has taken place, the gap between elderly Americans and elderly Britons goes on increasing with age. Although exposure to better technology may plausibly have an effect that cumulates with age, it is hard to see why age should narrow the gap prior to the availability of Medicare. The second problem with the access story is that the differences between British and American mortality rates do not seem to have changed after the introduction of Medicare in the late 1960s. The pattern of relative mortality by age was established prior to the introduction of Medicare.

A more satisfactory account of relative mortality in the two countries recognizes the benefits of universal access, but notes the low levels of health-care financing in Britain, not only relative to the US, but also relative to other OECD countries, see for example Gerdtham and Jönssson (2000, Table 1). The consequent rationing of health care in Britain is in many cases based on age, with the elderly (sometimes including people in their 50s) frequently denied access to expensive technologies from which they are likely to benefit, kidney dialysis being only the clearest example, see Aaron and Schwartz (1984). As Aaron and Schwartz also make clear, there are great differences in the way that new technologies are introduced in the two countries. In the competitive health-care industry in the US, there is great pressure to adopt new technologies as soon as they are feasible, essentially irrespective of cost. This certainly happened with the technologies that are important for the mortality changes discussed in this paper, the construction of neonatal facilities for low birth-weight babies, and the adoption of angioplasty and by-pass 
surgery. In Britain, by contrast, with its centralized National Health Service, expensive new technologies cannot be adopted without central government approval, which needs to wait for demonstrated effectiveness and the release of funding. Even then, access to the technologies is restricted, especially by age. These differences in institutional structure generate about a four year lag between the introduction of expensive new technologies in the US and in Britain, and this provides us with the opportunity to assess the effects of these technological changes on mortality.

We should note that our analysis, although helping to explain the patterns in the data, is silent on the relative merits of the two systems. Although the American system generates lower mortality rates at higher ages, the increases in life-expectancy will sometimes be small, and the cost very great. The British system spends relatively little, and has higher life-expectancy at birth.

\section{Age specific mortality, incomes, and income inequality}

\subsection{Summary of previous work}

We begin with a brief summary of the theory that motivated our earlier empirical work in Deaton and Paxson (2001). In that paper, we examined the extent to which income is protective against mortality, and whether income inequality is associated with higher mortality. Our starting point was a simple model in which each person's health status $(h)$ is assumed to be a function of his or her income $(y)$ relative to the average income of those in the person's reference group $(z)$. Assuming a linear relationship between health and (the logarithm of) income, the expected value of health conditional on $y$ and $z$ is:

$$
E(h \mid y, z){ }^{\prime} \alpha \% \beta(y \& z) .
$$


The reference group could be defined by geography or other characteristics. If $z$ is a fixed number for all individuals, then (1) collapses to a model in which health is determined solely by ownincome.

Equation (1) has several implications for the relationship between health, income, and income inequality. First, given that reference groups are not observable, (1) is not estimable. Instead, we must work with the expectation of health conditional on own income. Assuming that $y$ and $z$ are jointly normal, this conditional expectation can be expressed as:

$$
\left.E(h \mid y){ }^{\prime} \quad \alpha \% \frac{\beta \sigma_{\varepsilon}^{2}}{\sigma_{\varepsilon}^{2} \% \sigma_{z}^{2}}(y \& \mu)\right)^{\prime} \quad \alpha \% \beta^{(}(y \& \mu)
$$

where the marginal distribution of $z$ is assumed to be $N\left(\mu, \sigma_{z}^{2}\right)$ and the distribution of $y$ conditional on $z$ is $N\left(z, \sigma_{\varepsilon}^{2}\right)$, so that $\sigma_{\varepsilon}^{2}$ and $\sigma_{z}^{2}$ are measures of within reference group and between reference group inequality.

Two main conclusions are drawn from (2). First, if the reference group model is correct, estimates of $\beta^{*}$ will differ from $\beta$, with the extent of the bias a function of the relative sizes of the within and between group variances. If within-reference group inequality is small, then individual income is a poor measure of relative income, and the estimated income gradient in health will be small. If, on the other hand, within-reference group inequality is large relative to between reference group inequality_-which might be the case if reference groups are defined by large geographical areas, entire birth cohorts, or by entire populations of countries—-then $\beta^{*}$ will be close to $\beta$.

The second conclusion is that models in which health is determined by relative income do not necessarily imply that inequality will be harmful to health. In (2), inequality affects the slope of the 
gradient, but does not appear as a separate determinant of health outcomes. This result is driven by the assumption that individuals compare themselves to the mean income level in the reference group. If, instead, what matters is income relative to income at the top of the distribution within the reference group, a mean-preserving spread in income will harm the health of all those with incomes below the top of the distribution. Although this assumption delivers the result that inequality is harmful to health, other assumptions and outcomes are possible. For example, if rank within the reference group is what matters for health, then changes in inequality will not increase or reduce health (given income). Likewise, if what matters is income relative to the lowest income within the reference group, then mean-preserving spreads in income will improve health of all but the poorest.

In our American and British work, we estimate models that relate the mortality experiences of birth cohorts to income and income inequality within the cohort. Since we work on a year by year basis, our procedures are also equivalent to working with people at a given age in a given year. Aggregation within cohorts (or age groups) can introduce a relationship between mortality and inequality even if there is no relationship at the individual level. By Jensen's inequality, if health is increasing but concave in income (or, conversely, if the relationship between the probability of mortality and income is decreasing but convex), then a mean-preserving spread in within-cohort income will reduce average health. Aggregation to the cohort level also has implications for the slope of the gradient. If reference groups lie "within" cohorts—so that what matters for health is own income relative to income of some group of individuals born in the same year-then aggregation will annihilate the relationship between health and income. On the other hand, if reference groups cut across cohorts, then estimation using the aggregated data will provide 
information on the gradient — although the slope of the gradient may be attenuated as in (2). These points are discussed in more detail in Deaton and Paxson (2001).

\subsection{Data}

In the following section we extend our earlier work on mortality, income and income inequality from the United States to Britain, or more precisely to England and Wales. (Britain is England and Wales plus Scotland; the UK is Britain plus Northern Ireland.) Income measures are drawn from the 1971-1998 rounds of the British Family Expenditure Survey (FES). The FES has information on households in England, Wales, Scotland, and Northern Ireland. We excluded households from Scotland and Northern Ireland so as to match the income to the mortality data.

As in the American work, we combine the mortality and income data together at the level of the birth-cohort in each year, or equivalently, on an age/year basis. We restrict our analysis to groups of individuals aged 25 to 85 . There are approximately 11,000 observations on individuals (both men and women) in this age range in any single survey year of the FES, and there are on average 85 observations within each cohort-age-gender cell. The FES is used to compute averages (or medians, variances, etc.) of income and education variables for each cohort-agegender cell. These data are then merged with the mortality data by cohort, age and gender. When the two data sources are combined, we are left with individuals born from 1886 (aged 85 in 1971) to 1973 (aged 25 in 1998). For a small number of birth cohorts at some advanced ages, there are no individuals in the FES. Our final data set upon merging consists of 1680 cohort-age cells for men and 1706 cohort-age cells for women. 
Our income measure is normal gross weekly household income. We adjust for household size by dividing income by the number of "adult equivalents" in the household, where children under the age of 18 count as half of an adult. In most of our analyses we use the average of the logarithm of income per adult equivalent as our measure of resources. For measures of dispersion we use the gini coefficient and the variance of the logarithm of income per adult equivalent. The education variables we use require discussion. From 1978, the FES has information on the age at which the individual left full-time schooling. We convert this to years of schooling by assuming that education starts at age 5. There were a small number of cases of individuals who reporting finishing full-time schooling after the age of 25 (with one 72-year-old reporting that full-time schooling did not end until age 52.) In these cases we restricted our measure of years of schooling to 20 . Because information on education was not available prior to 1978 , our sample period is 1978-1998 when we use information on education.

The FES also contains some information on tobacco use, which is an important determinant of health. The FES does not directly ask respondents if they currently smoke, nor does it collect any information on smoking history. However, it does collect individual-level data on tobacco purchases during the reference period. We construct an indicator for smoking which is set to one if the individual purchased any tobacco. This smoking measure is far from perfect. Individuals may purchase tobacco for others, or have it purchased for them. In addition, there is evidence that tobacco purchases in the FES are under-reported (Goodman and Webb, 1999.) Finally, previous as well as current tobacco use may affect mortality. These factors are likely to attenuate our estimates of the relationship between tobacco and mortality. Nevertheless, when looking at the 
influence of income on mortality, it is useful to be able to control for tobacco use, albeit imperfectly.

In many of the results that follow, we contrast British results with results from the US, drawn from Deaton and Paxson (2001.) The US data are constructed in the same way as the British data. The mortality data are from the Berkeley mortality data base and the income information is calculated from the 1976-1996 waves of the March Current Population Survey. The variable definitions are similar, with a few small exceptions. One is that income is annual before-tax household income, rather than normal gross weekly household income. Another is that schooling is based on questions about the grade level attained rather than the age at which schooling was completed. Further details on the data from the U.S. are provided in Deaton and Paxson (2001.)

\subsection{An empirical formulation}

There are several possible ways of using age/year data to examine the effects of income and income inequality on mortality. An important requirement for a suitable empirical model is that age and time trends be flexibly incorporated, so that their effects are not inappropriately projected on to the income variables. Beyond age 20 or so, mortality increases monotonically with age. Income inequality also increases with age, and income has the characteristic life-cycle pattern of increase and decline. If age-specific mortality is not flexibly modeled, there is a danger that we ascribe some of the effects of age to income or income inequality. Similar arguments apply to time trends. Mortality has a background underlying downward trend, and it makes little sense to spuriously match this to the trends in income and income inequality.

To avoid these difficulties, we start from the specification: 


$$
\ln o_{a t}{ }^{\prime} \quad \beta_{0} \% \beta_{1} t \% \alpha_{a} \% \gamma_{a t} \% \varepsilon_{a t}
$$

where $\ln o_{a t}$ is the log odds of mortality for the group aged $a$ and observed in year $t . \beta_{0}$ and $\beta_{1}$ are parameters, $t$ is a time trend, $\alpha_{a}$ is an unrestricted set of age dummies, one for each year of age, and $\varepsilon_{a t}$ is a residual. The term $\gamma_{a t}$ needs to be further specified in order to give the model content. One possibility would be a cohort model in which $\gamma_{a t}{ }^{\prime} \theta_{t \delta a}$ and thus varies only by year of birth; versions of this model were explored in Deaton and Paxson (2001). Alternatively, we can use $\gamma_{a t}$ as a vehicle for the economic variables. For example, one model that we explore is where $\gamma_{a t}$ is a linear function of (for example) mean family income and mean years of education for people aged $a$ in year $t$, and of income inequality within the age group in that year. so that

$$
\gamma_{a t}{ }^{\prime} \gamma_{1} \bar{y}_{a t} \% \gamma_{2} \bar{s}_{a t} \% \gamma_{3} g_{i n i}
$$

We shall also estimate such models separately for different age groups, which effectively allows the coefficients in (3) and (4) to be functions of age. Such a specification is very close to the leading statistical model of mortality in the demographic literature, that of Lee and Carter (1992). Their model is for the logarithm of the mortality rate itself, rather than the log odds, but the two measures are close when the probability of death is small, and they write

$$
\ln p_{a t}{ }^{\prime} \quad \tilde{\alpha}_{a} \% \tilde{\beta}_{a} k_{t} \% u_{a t}
$$

where $\tilde{\alpha}_{a}$ and $\tilde{\beta}_{a}$ are unrestricted age coefficients, and $k_{t}$ is a random walk with (downward) drift so that, with innovation $v_{t}$

$$
k_{t}{ }^{\prime} k_{t \& 1} \% \tilde{\beta}_{1} \% v_{t}
$$

In their estimations, the random walk with drift is very close to a time trend, so that (5) is in practice very close to (3) with age-specific coefficients on the time trend and $\gamma_{a t}$ omitted. 
Although models such as (1) and (5) fit the data well, they have a number of deficiencies for our purposes, and indeed more generally. Because all age-specific mortality rates are assumed to share the same trend, either a simple linear trend in (1), or a random trend in (5), these models cannot recognize episodes in which age-specific mortality rates deviate for a substantial period from their long-run trends. In our current data, this is a problem for the younger adult groups whose long term mortality decline has been interrupted in recent years by mortality related to AIDS (see Figures 3 and 5). As a result, we run some risk of spuriously attributing the spread of an infectious disease to any economic events that happen to coincide with it, again see the discussion in Section 2 above. More generally, equations (3) and (4) allow economic variables to play a role only once unrestricted age effects and time trends have been eliminated. But as Lee and Carter's work makes clear, these variables by themselves give a good account of the data so that, given our concern not to impute too much to economic variables, the specification may allow them too little information to work with. While recognizing the problem, we currently see no way of dealing with it.

Figure 7 shows long-term information on cohort mortality in the UK and US, and highlights some of the difficulties of modeling the time-series properties of mortality. Each graph shows the $\log$ odds of mortality for every $20^{\text {th }}$ cohort, starting with those born in 1870 and ending with those born in 1970. The UK and US patterns share many of the same features. The log odds of mortality declines sharply after infancy, and after age 30 increases roughly linearly with age. Although there were mortality declines at all ages for both sexes over this period, the patterns differ across age groups. The declines were particularly rapid for women of child-bearing age in the early part of the $20^{\text {th }}$ century. In addition, mortality declines at older ages are more 
pronounced for women than for men. The mortality experience of both countries shows evidence of the influenza pandemic of 1919 (and, for British males, deaths associated with the First World War.) Finally, in both countries there is a marked slowing of mortality decline among young men born in the latter half of the $20^{\text {th }}$ century. In many of the results that follow, we omit the youngest groups of men (aged 25 to 34 ) so that the slowdown in mortality decline due to HIV/AIDS does not affect the analysis.

\subsection{Income, Income Inequality and Mortality}

We start by examining the relationship between mortality and the level of income. Table 1 contains the first set of regression results using the specification shown in (3), in which we assume that $\gamma_{a t}$ is a linear function of the average of the logarithm of income per adult equivalent. The regressions are estimated separately for men and women, for the full sample of 25-85 year-olds, and for four smaller age ranges. We report only the estimates of the coefficient on income. The first three columns of estimates and $t$-values are for the United States, with and without the time trend and, in the third column, with an interaction of the time trend with age. This last specification is similar to Lee and Carter's formulation in that it allows the effects of a common trend to vary across ages. The last three columns repeat these equations for Britain.

When time trends are excluded from the regressions, the estimates are closely comparable for the US and Britain. For all age groups combined, the logarithm of income per equivalent is protective against mortality, with a coefficient of -0.56 (men) and -0.53 (women) in the US and -0.64 (men) and -0.77 (women) in the UK. Apart from the 25-39 year old group of males in the US, whose mortality rates have been increasing in recent years (again see Figure 4) and whose 
mortality rate is estimated to respond positively to increases in income, the age group estimates are also similar across the two countries. In both cases, income is most strongly protective in middle-age. As we showed in Deaton and Paxson (2001), these protective effects of income are close to those estimated from the individual level data from the National Longitudinal Mortality Study in the US. We also argued, based on the model of reference groups, that this correspondence of the two sets of estimates was to be expected if, as seems likely, reference groups cut across cohorts, rather than being confined within them.

The inclusion of time trends upsets this conformity of results across countries and data sets. (Similar results are obtained when a complete set of year dummies are included instead of a time trend.) In the US, when all ages are pooled, the time trend reduces the estimated effect of log income but does not eliminate it. However, including the time trend does change the sign of the income coefficient for the older age groups. Results in Deaton and Paxson (2001) indicate that when a time trend is included but income is instrumented with a set of cohort dummies and with a measure of schooling, the effect of income is similar to that originally estimated with no trend. It is questionable whether the cohort dummies and years of schooling are valid instruments for income in a mortality regression. Schooling, in particular, may have independent effects on health. However, the fact that the use of these instruments yielded sensible results that lined up with those found in micro data (from the National Longitudinal Study) provided some ex post justification for their use.

The results for the UK with the trend included are quite different from results with no trend and from the US results. In Britain, the inclusion of a time trend essentially eliminates any estimated role for income, a result which will not be reversed in any of the other specifications we 
report below. Indeed, in most cases (men of all age groups, and both men and women aged 55 to 69) higher cohort income appears to be associated with higher mortality rates. The addition of the interaction term between the trend and age has some effect on these results—specifically, the positive and significant association between mortality and income for those aged 55 to 69 disappears. However, in no case is income estimated to be significantly protective. Finally, using the British data, the instrumentation strategy described above did not restore the protective effect of income.

Figures 8 and 9 explore why the results are so different in the two countries. The starting point for these graphs are two matching regressions, one of the log odds of mortality on a set of age dummies and a time trend, and another of the logarithm of income per adult equivalent on the same variables. The residuals of these regressions are averaged (by year in Figure 8, and by birth year in Figure 9) and then plotted against one another so that we can see how the behavior of the mortality rates matches the behavior of log income, once allowance has been made for age effects and time trends in both. Both figures show plots for males on the left and for females on the right, with Britain on the top and the US on the bottom. In Figure 8 the residuals are plotted against time, so that the graphs show the average residuals over all cohorts in each year of the log odds of mortality and the logarithm of income. In Figure 9, the plot is against year of birth, so that the averaging is over all years for each cohort.

Figure 8 indicates that the year-averaged mortality and income residuals are not negatively related for either country. Regressions of one on the other yield coefficients for income that are small—sometimes positive and sometimes negative—and not significantly different zero for males and females in both countries. The cohort-averaged residuals in Figure 9 have different patterns. 
For the US, there is a negative relationship between the income and mortality residuals. The coefficient on income from a regression is $-0.54(t=4.6)$ for males and $-0.45(t=6.2)$ for females. For the UK, these coefficients are $-0.05(t=0.18)$ for males and $-0.15(t=.89)$ for females. Note, however, that these results hinge on the experience of cohorts born after 1930. For those born earlier (many of whom were retired by the start of our sample period) there is no apparent relationship between income and mortality in either country.

We do not have an explanation for the differences in results across Britain and the US. It is especially difficult to piece together a story that reconciles these differences and is also consistent with existing evidence from micro-level data for both countries. For example, one possible explanation of the cohort-level results shown here is that the relationships between income and health in the US and Britain are genuinely different from each other. The provision of national health care may break the link between health and income in Britain, so that income is important in the US but not in Britain. Although plausible, this explanation is at odds with micro-level evidence from the Whitehall studies (Marmot, 1994) that show a strong positive relationship between socioeconomic status and health. The Whitehall results typically use occupation or education rather than income as an indicator of socioeconomic status. However, education and occupation are highly correlated with income, and since we do not control for education or occupation in Table 1 we would expect income to capture the general effects of socioeconomic status.

Another possible explanation is that our earlier conclusions about the US were wrong, and that income is not important for health in either country. The results in Table 1 do not provide very strong evidence that income affects mortality in either country, at least when the time trend is 
included. In Deaton and Paxson (2001), the US results with a trend were consistent with the micro evidence only after applying a set of instruments of questionable validity. And, the relationships between income and mortality found in the micro data could be due to the effect of health on income, so that individuals in poorer health both earn less and are more likely to die. However, it is difficult to dismiss the micro evidence so easily. For example, Case, Lubotsky and Paxson (2001) find that the income gradient in health begins early in childhood, a period when it is not plausible that health drives income.

It may be more sensible to focus on the relationship between mortality and education rather than income. Education is sometimes a better measure of long-run resources than is current income, and it may be that it is long-run rather than current incomes that matter for health. Education may also affect how well individuals are able to make use of new medical technologies and information or be directly productive of health, Lleras-Muney (2000). Our earlier work from the US indicates that controlling for education eliminates the protective effect of income when using the cohort-aggregated data (although not when using the micro-data from the National Longitudinal Mortality Study.) Evidence from Deaton and Lubotsky (2001) using US city-level data indicate that the association between income and mortality vanishes once controls for education are introduced.

Table 2 shows regressions of the log odds of mortality on both income and mean years of schooling. Age dummies and a time trend are included in each regression. The first column shows US results. As in Deaton and Paxson (2001), schooling has a large, negative, and significant association with mortality. When education is included, income appears to be hazardous for males, possibly reflecting the counter-cyclical pattern in mortality discussed by Ruhm (2000). 
Income is either hazardous or insignificant for females. The British results show a very similar pattern. However, the effects of both income and education are much smaller than in the US. For example, a 1-year increase in education is predicted to reduce the odds of mortality for all males by 11.5 percent in the US, and only 2.0 percent in the UK. These results could be due to genuine differences in the provision of health care between Britain and the US. However, they are also consistent with the hypothesis that it is neither education nor income that matters, but some third factor that is less correlated with education in Britain, where the variation in education is much less.

The third column adds a control for the fraction of the individuals in the cohort that reports purchases of tobacco. These regressions can only be run for Britain, not for the US. We include tobacco not only because it is likely to be associated with mortality, but also because its use may be correlated with income and education, and it is useful to see whether its inclusion affects the results. As expected, mortality is usually higher in cohorts where the fraction of smokers is high. One exception is among men from 60 to 85 where smoking has no effect on mortality; perhaps those at risk have already been selected out by this age. However, the treatment of tobacco does not change the behavior of the estimates of income or education. As before, income is estimated to be either insignificantly different from zero or hazardous, and education is generally protective.

In Table 3 we turn to the role of inequality, measured by the gini coefficient for incomes within the cohort. We also look at the fraction of the cohort that is unemployed, following the literature that argues that unemployment raises the risk of death. As is the case for inequality in the US, the estimated effects of inequality on mortality are perverse. Higher income inequality in both countries inequality is associated with lower mortality, though note that the effect is only 
significantly different from zero for younger and older men in the US. Adding years of schooling and smoking does not affect this conclusion, nor does adding the unemployment rate. There is no clear pattern in the association between the fraction unemployed and mortality. Unemployment is estimated to be protective of health for all women, and hazardous to health only for the group of older men, most of whom are retired. Unemployment has no effect on mortality for the younger working-aged groups for whom the effects might be expected to be the largest.

Taken together, the results for Britain are not supportive of the idea that either income or income inequality affect mortality. The only consistent patterns we find are that education is (mildly) protective, and that smoking is a health hazard. Part of the reason for these findings may simply be that we are asking too much of the data. Including the time trend may be removing most of the variation in the data in which we are most interested, making it possible to identify the effects of income. However, excluding the trend is not a sensible option, since secular changes in mortality are likely to load onto trends in income or income inequality.

\subsection{Pooling data from Britain and the US}

All of the results so far analyze the US and Britain separately. In this final subsection, we ask whether anything can be learned by pooling the data and exploiting differences in income and mortality between the US and Britain. Pooling the data may in theory solve the problem of identification in the presence of trends. Under the (strong) assumption that the two countries share the same technologically-driven trends in mortality, it is possible to identify the effects of income by examining how changes in the relative incomes of same-aged individuals in the two countries are related to relative differences in mortality. 
Table 4 shows estimates of models of the following form:

$$
\ln o_{c a t} ' \delta_{c} \% \gamma_{y} \% \lambda_{a} \% \beta \ln (y / a e)_{c a t} \% \varepsilon_{c a t}
$$

where $\ln o_{c a t}$ is the $\log$ odds of mortality for those in country $c$ at age $a$ and year $t$, the first three terms on the right-hand-side are country, year and age fixed effects, and $\ln (y / a e)_{c a t}$ is the logarithm of income per adult equivalent. This equation is estimated separately for men and women. The sample is restricted to the years 1975-1995, so that both countries are represented in all years. We report results with all ages pooled, although the results are similar when we break the sample into older and younger age groups.

The first four columns of Table 4 show estimates that are not pooled, and replicate the basic findings discussed above. (Differences from previous results reflect the different sample period, for Britain, and the use of a complete set of year dummies rather than a time trend.) In the first two columns, we estimate the model separately for each country, with no year dummies. As before, income is protective in both countries for both men and women. The American and British results are remarkably similar. The second two columns add year dummies. In line with all of our results so far, this has the effect of reducing but not eliminating the estimated gradient for the US, but reversing the sign of the income to health gradient for Britain.

In the final two columns we present pooled results. With no year effects, we obtain the usual large negative and significant coefficients for income: -0.89 for men and -0.64 for women. Adding year effects does not alter this result: the coefficient on income for males is essentially unchanged, and that for females declines by less than a quarter.

Figure 10 presents the data in way that elucidates these results. We computed the difference in the log odds of mortality between Britain and the US for each age-cohort cell, and also the 
differences in the logarithm of income within each age-cohort cell; the currencies were converted to common units using PPP exchange rates from the OECD website at http://www.oecd.org/std/nadata.htm. The top two panels average these differences by year (males are on the left, and females are on the right.) The bottom two average these differences by year of birth. The birth-year averaged figures are especially illuminating. For males and females, the difference between British and American mortality declines steadily over time, so that morerecently-born British cohorts have lower mortality relative to their American counterparts than do cohorts born earlier in the $20^{\text {th }}$ century. Similarly, although British incomes are always below American incomes, the relative difference has declined, so that the most recently-born cohorts of British males have incomes that are similar to their counterparts in the US. The opposite slopes of these two curves account for the large negative relationship between mortality and income in the pooled regressions. The picture is much the same for females, although for this group there is an initial decline in relative British incomes between those born in 1890 and those born around 1910. (This decline also appears for men, but is more muted.) The negative relationship is less apparent in the top year-average figures, in which the income differences are dominated by the sharp British recession in the early 1990s.

Although these results indicate that there is a negative association between income and mortality, at least over the longer run captured by the cross-country comparisons, there are reasons to treat them with some skepticism. First, they are based on the assumption that health technology is identical in the two countries: in the regression results and (implicitly) in the graphs we are assuming that year and age effects are identical across the two countries. In fact they are not. The bottom panel of Table 6 presents $F$-tests for the equality of the age and year effects in 
the pooled model. The hypothesis that the age effects are identical is strongly rejected for both men and women. Consistent with the time-series results discussed in Section 2, the unrestricted age effects indicate that mortality increases faster with age in Britain than in the US for both men and women (although somewhat more so for men). It is also invalid to restrict the year effects to be the same across the two countries-which is not surprising, given our results in Figures 2 and 3 that suggest that British technology lags that of the US. The unrestricted year effects show mortality declines over the period that are somewhat larger in Britain than the US.

\section{Conclusions}

In both Britain and America, for men and for women, and for most age groups, there has been a very substantial decline in mortality rates since 1950 . Our examination of these rates, by sex and age group, and in relation to the evolution of incomes and income inequality, does not suggest any simple relationship between income growth and the decline in mortality, nor between income inequality and mortality rates. In the United States, the period of slowest income growth saw substantial accelerations in the rate mortality decline, particularly among middle-aged and older men and women. In both the US and Britain, the increase in income inequality took place at the same time as a deceleration in mortality decline at the younger ages, including infant mortality. But there are previously slow rates of decline when nothing was happening to income inequality, and the later rise in income inequality was associated with the acceleration in mortality decline among middle-aged and older adults in both countries. A more plausible account of the data is that, over time, declines in mortality are driven by technological advances, or by the emergence of new infectious diseases, such as AIDS. These advances and retreats are associated with specific 
conditions and specific treatments, and so affect men and women differently and different age groups differently. They also happen first in the United States, with the British experience following with a lag of several years. Clearly this hypothesis needs a great deal more investigation, for example, by looking at more countries and at specific causes of death.

If changes in mortality over time are driven by technology, and not by income, there must be some doubt as to whether our previous analysis in Deaton and Paxson (2001) came to the correct conclusions about the role of cohort incomes in the decline of cohort mortality. Certainly, our results cannot be replicated on the British data. Simple regressions of the log odds of mortality on $\log$ income per equivalent and on age dummies give similar results in both countries, with income estimated to be strongly protective, but the addition of time trends destroys the result in the Britain, and weakens it in the US. Education reduces mortality among British cohorts, and smoking increases it. But neither these sensible results, not the inclusion of other variables, repairs our inability to produce coherent and stable effects of income on mortality at the cohort level. We suspect—but have been unable to demonstrate decisively—that the cohort analysis is flawed by the necessity to make the almost certainly invalid assumption that age effects in mortality are constant through time. This is contradicted, for example, by the spread of AIDS which has almost certainly raised the early life relative to later life mortality rates among recently born men and women compared with their seniors. If this is a serious problem, the cohort method may not be useful in this context, or at least require substantial modification in order to give sound results.

More substantively, we suspect that our time-series results in Section 2 are more reliable, and that such comparative international work is a productive direction for future research. Even so, there remains a major puzzle about the role of income. Income growth seems to play little role in 
the decline of mortality at the national level. At the cohort level, the same is possibly true, as argued above. Yet in the individual level data, from the National Longitudinal Mortality Study, as from many other data sets, income is protective against mortality, even when education and other socioeconomic variables are controlled for. Why there should be such a contrast between the individual and national effects of income is a topic that requires a good deal of further thought and analysis.

\section{References}

Aaron, Henry J., and William B. Schwartz, 1984, The painful prescription: rationing hospital care, Washington, D.C. The Brookings Institution.

Atkinson, Anthony B., and A. Brandolini, 1999, "Promise and pitfalls in the use of 'secondary' data sets: income inequality in OECD countries," Nuffield College, Oxford, processed. Available at http://www.nuff.ox.ac.uk/users/atkinson/ (Journal of Economic Literature, forthcoming.)

Brandolini, Andrea, 1998, “Pareto's Law and Kuznets' curve: a bird's eye view of long-run changes in income distribution," Rome, Banca d'Italia, Research Department, Rome, processed.

Case, Anne, Darren Lubotsky and Christina Paxson, 2001, "Economic status and health in childhood: the origins of the gradient," Princeton University, processed. Available at http://www.wws.princeton.edu/ chw/papersframe.html

Danesh, John, Peter Whincup, Mary Walker, Lucy Lennon, Andrew Thomson, Paul Appleby, Yuk-ki Wong, Martine Bernardes-Silva, and Michael Ward, 2000, "Chlamydia pneumoniae IgG titres and coronary heart disease: prospective study and meta-analysis," British Medical Journal, $321,208-213$.

Deaton, Angus and Christina Paxson, 2001, "Mortality, education, income, and inequality among American cohorts," in David Wise, editor, Themes in the Economics of aging, Chicago University Press for NBER. (NBER Working Paper No. 7140)

Deaton, Angus and Darren Lubotsky, 2001, "Mortality, inequality and race in American cities and states," Princeton University, processed. Available at http://www.wws.princeton.edu/ chw/papersframe.html 
Deininger, Klaus and Lyn Squire, 1996, “A new data set measuring income inequality,” World Bank Economic Review, 10, 565-91.

Gerdtham, Ulf-G., and Bengt Jönsson, 2000, "International comparisons of health expenditure," Chapter 1 in Anthony J. Culyer and Joseph P. Newhouse, Handbook of Health Economics, Volume 1A. Amsterdam. North-Holland.11-53.

Goodman, Alissa and Steven Webb, 1994, "For richer, for poorer; the changing distribution of income in the United Kingdom 1961-1991," London, Institute for Fiscal Studies, Commentary No. 42.

Goodman, Alissa and Steven Webb, 1999, "The Distribution of UK Household Expenditure, 1979-92." Fiscal Studies 16(3) pp. 55-80.

Gottshcalk, Peter and Timothy Smeeding, 2000, "Empirical evidence on income inequality in industrial countries," in Anthony B. Atkinson and François Bourguignon, eds., Handbook of Income Distribution, Vol. 1, Amsterdam, North-Holland. pp 261-307.

Jones, Arthur F., and Daniel H. Weinberg, 2000, "The changing shape of the nation's income distribution," P60-204, Washington, DC, Bureau of the Census. Available at http://www.census.gov/ftp/pub/hhes/www/p60204.html

Lee, Ronald D., and Lawrence R. Carter, 1992, "Modeling and forecasting US mortality," Journal of the American Statistical Association, 87, 659-71.

Marmot, Michael G., 1994, "Social differences in health within and between populations," Daedalus, 123, 197-216.

Lleras-Muney, Adriana, 2001, "The relationship between education and mortality: an analysis using a unique social experiment," Columbia University, Department of Economics, processed.

Ruhm, Christopher, 2000, “Are recessions good for your health?," Quarterly Journal of Economics, 115(2), 617-50..

Wald, N.J., M. R. Law, J. K. Morris, X. Zhou, Y. Wong, M.E. Ward, 2000, “Chlamydia pneumoniae infection and mortality from ischaemic heart disease: large prospective study," British Medical Journal, 321, 204-207.

Wilkinson, Richard G., 1996, Unhealthy societies: the affliction of inequality, London. Routledge. 

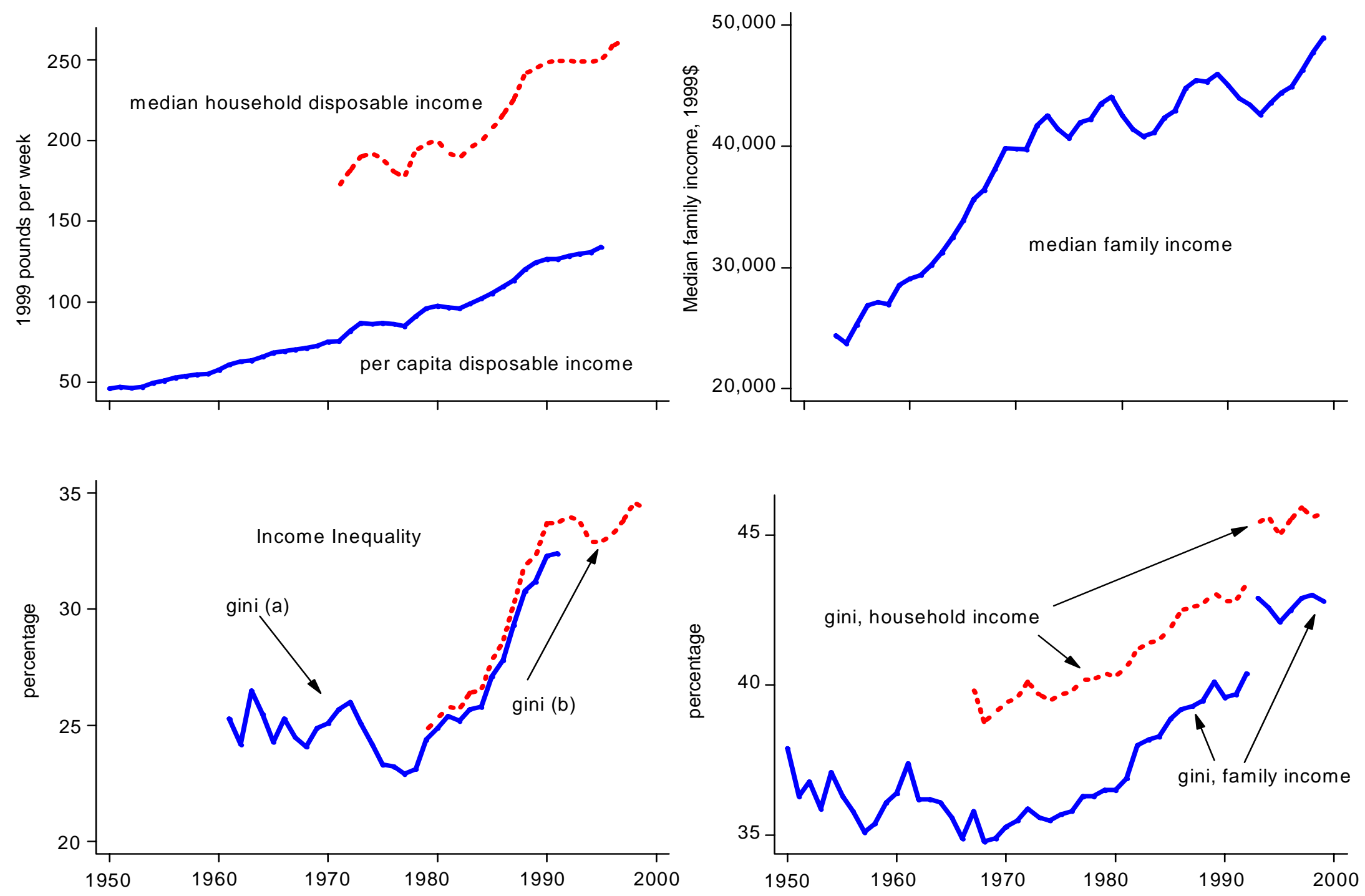

Figure 1: Income and income inequality, UK and US 

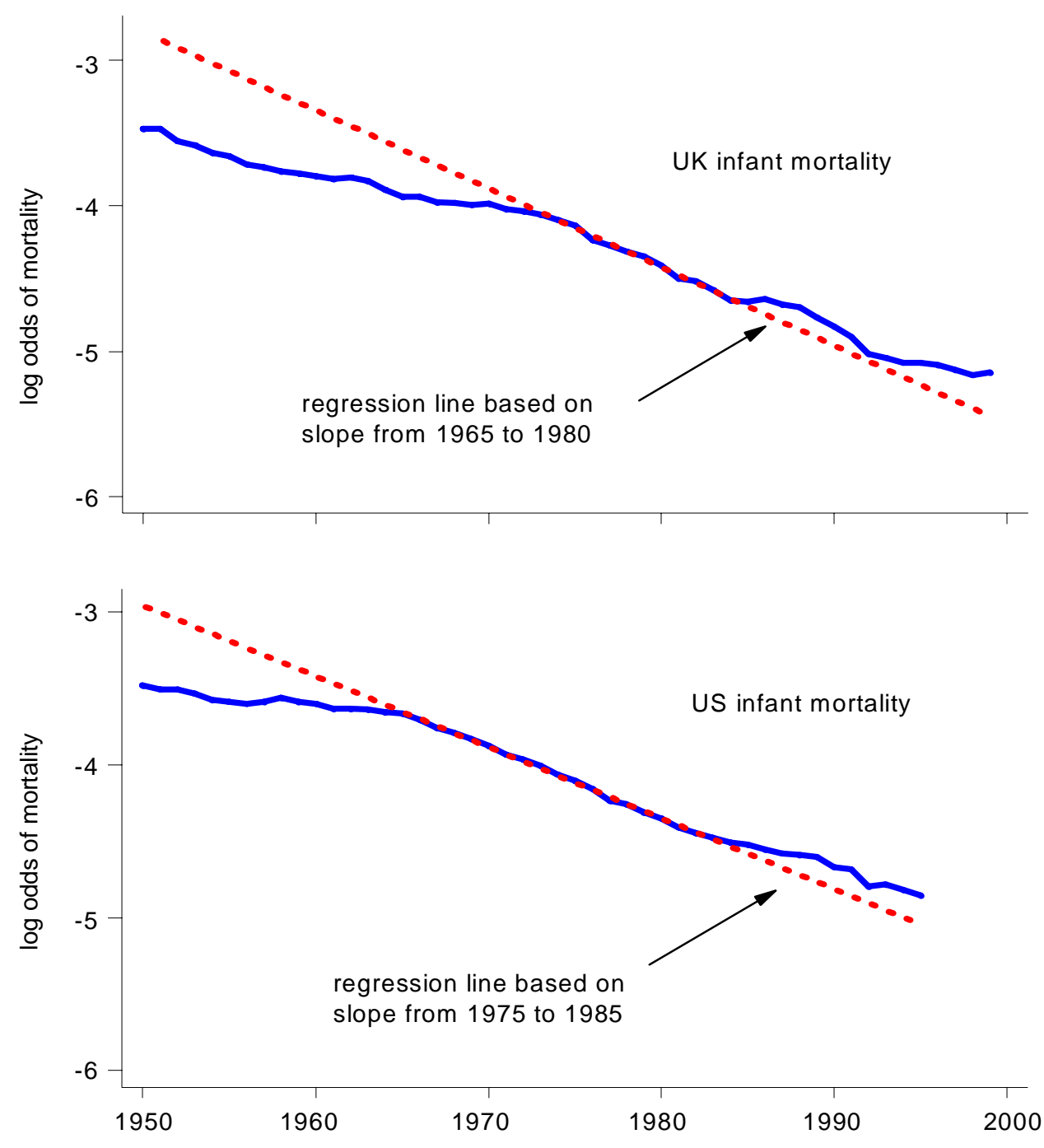

Figure 2: Infant mortality in the UK and US 


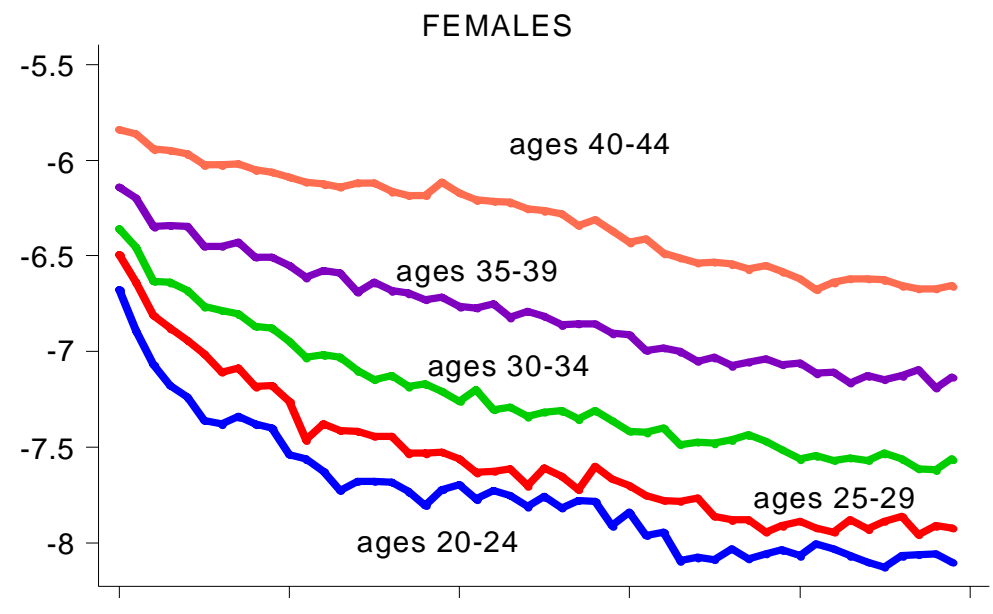

FEMALES

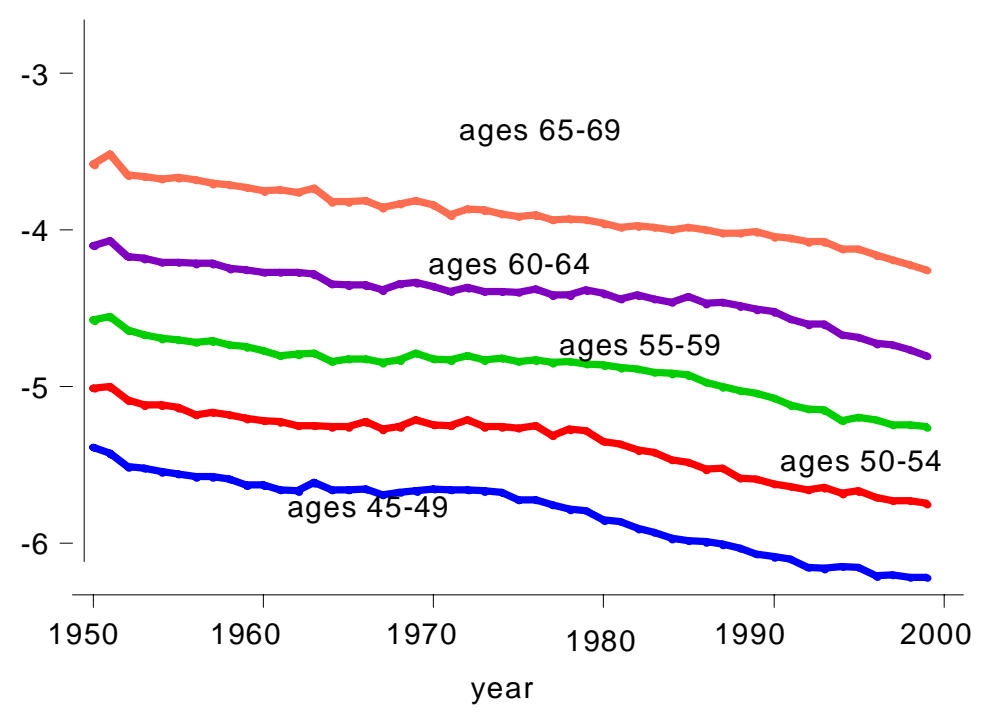

MALES

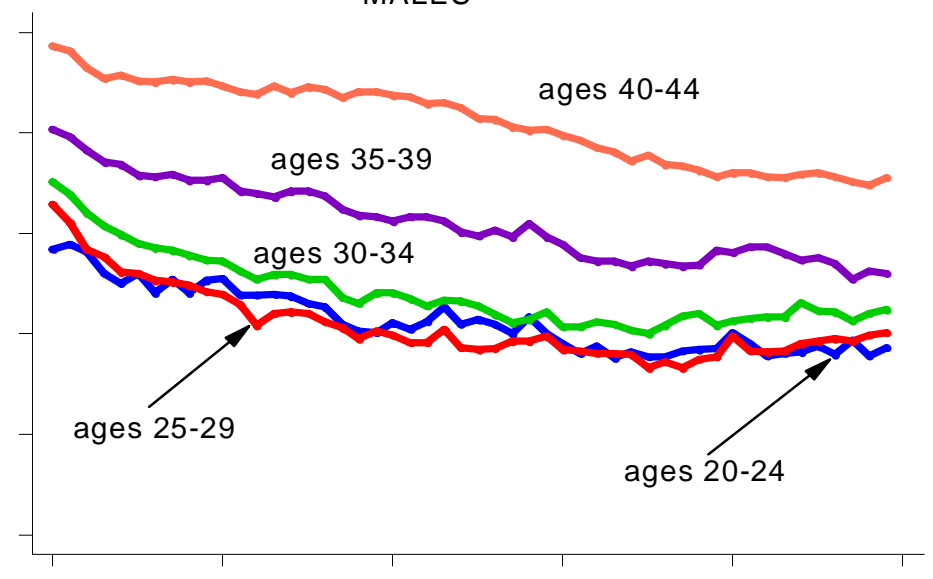

MALES

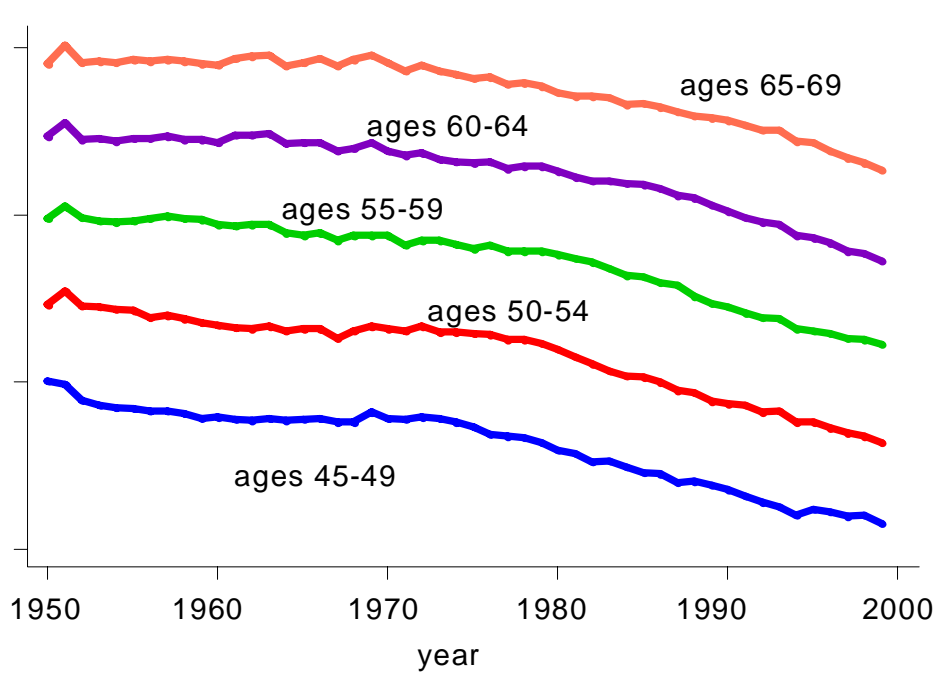

Figure 3: Adult Mortality, UK 

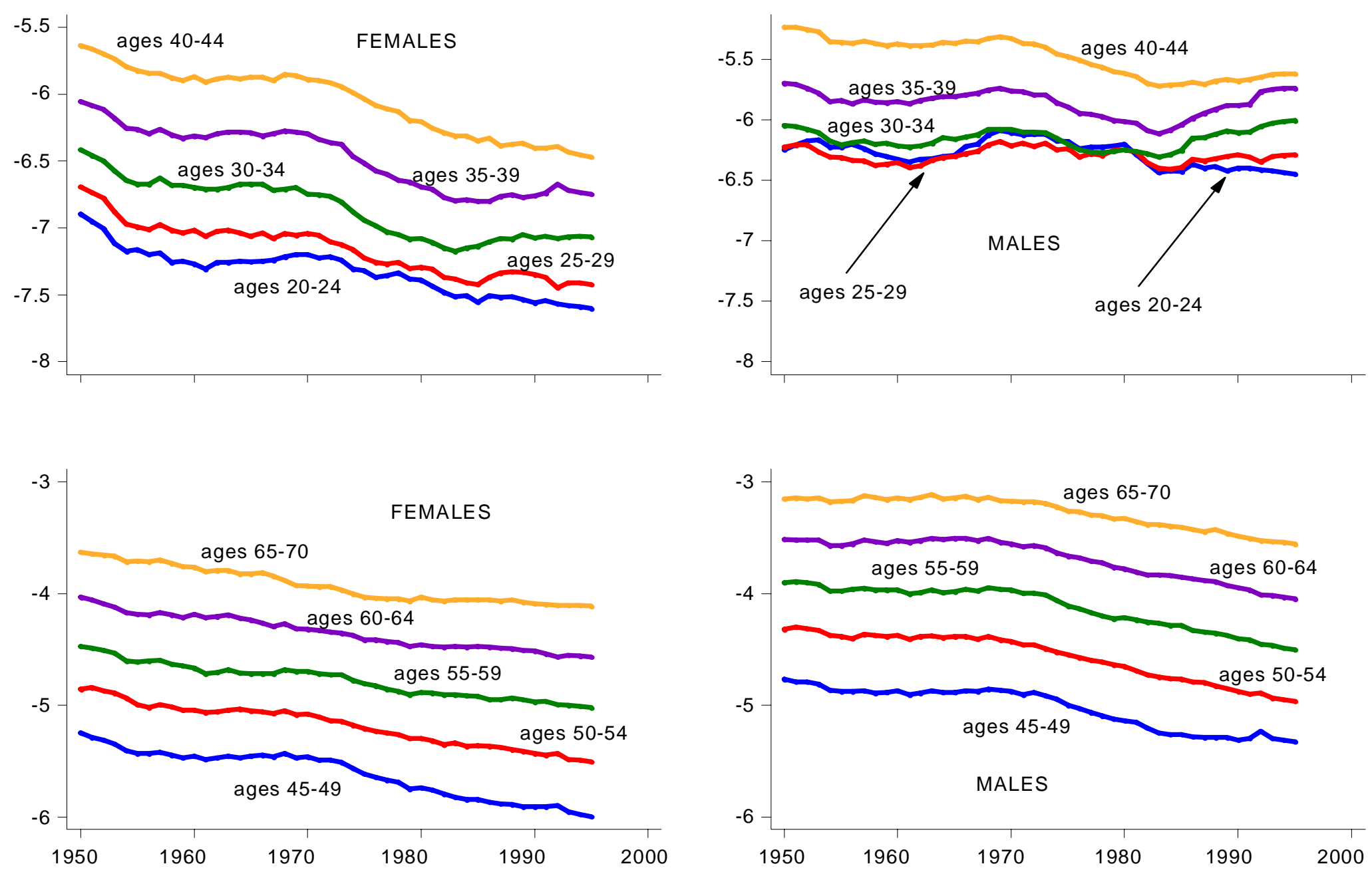

Figure 4: Adult Mortality, US 

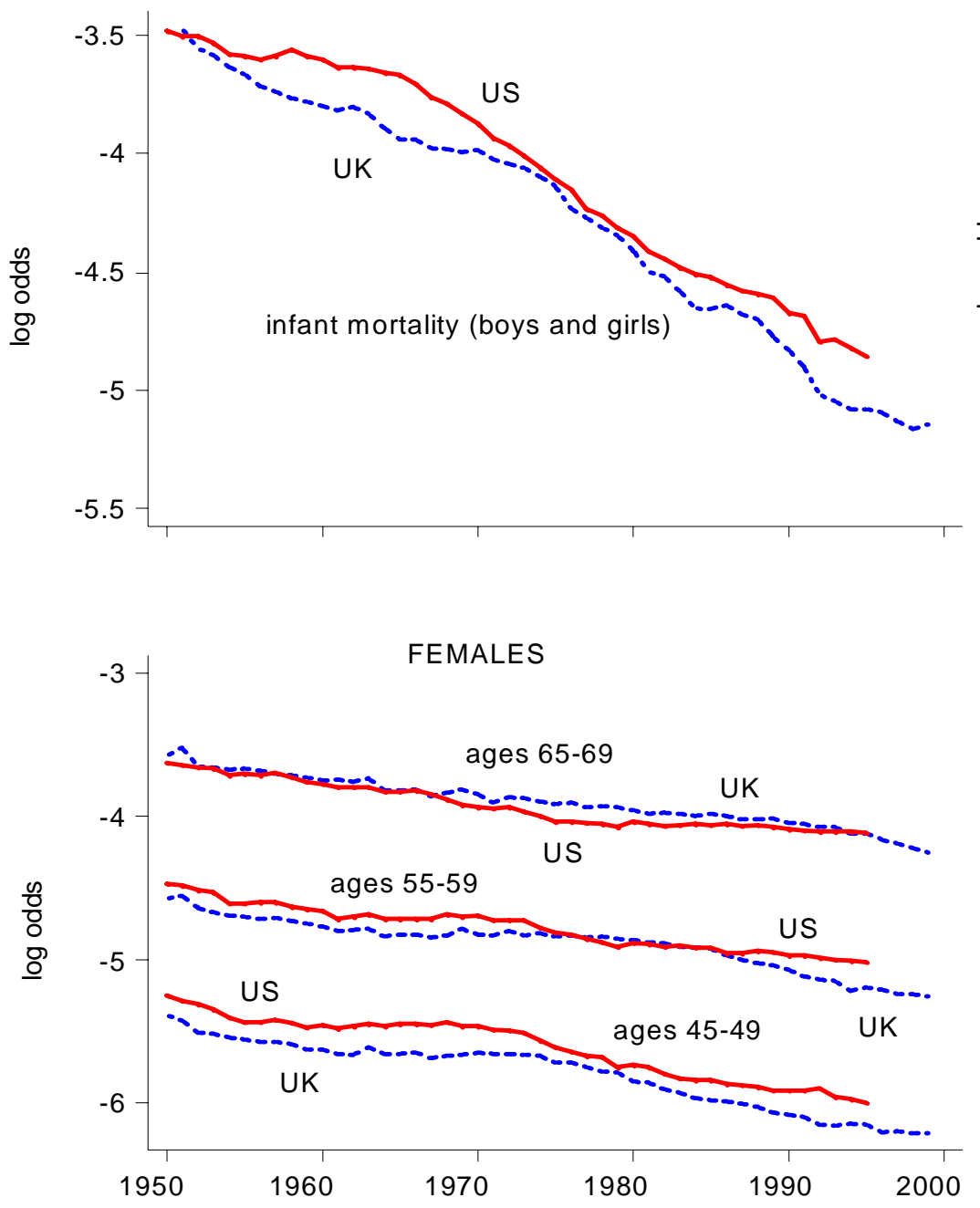

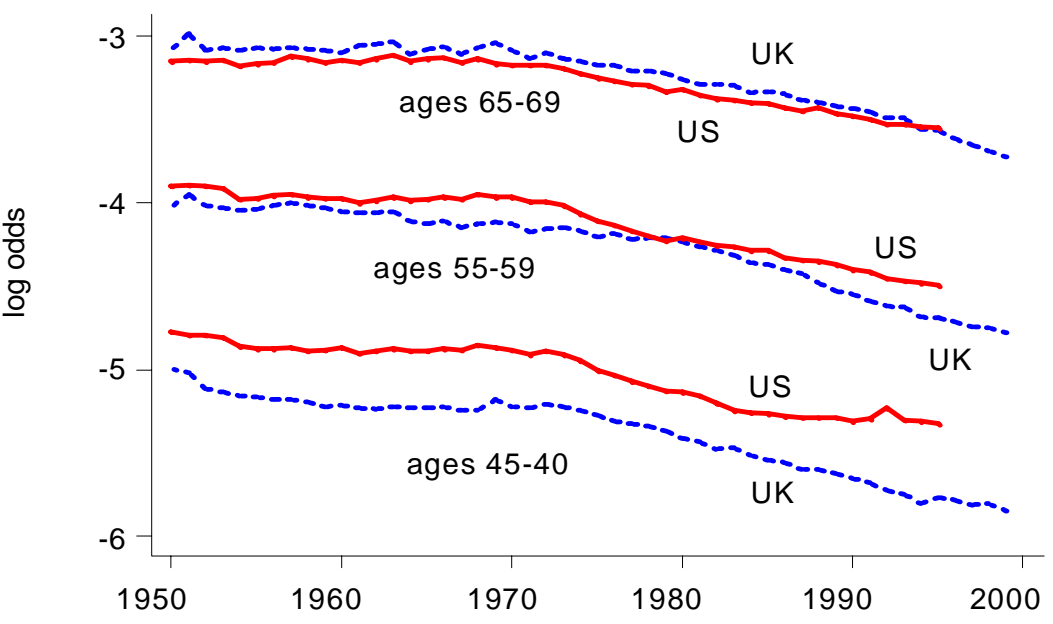

MALES

Figure 5: Adult Mortality, UK and US 

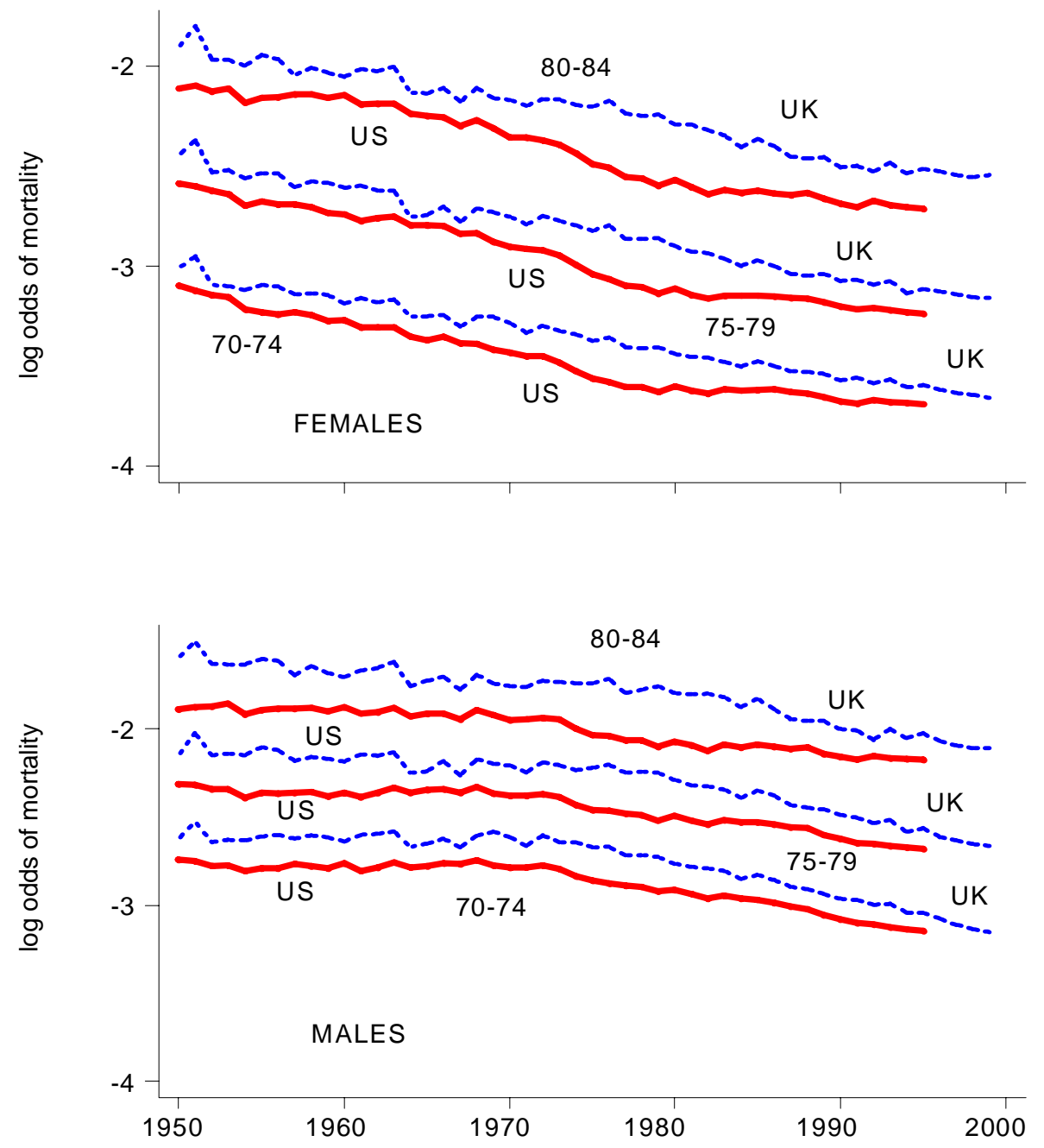

Figure 6: Mortality Among the Elderly, UK and US 

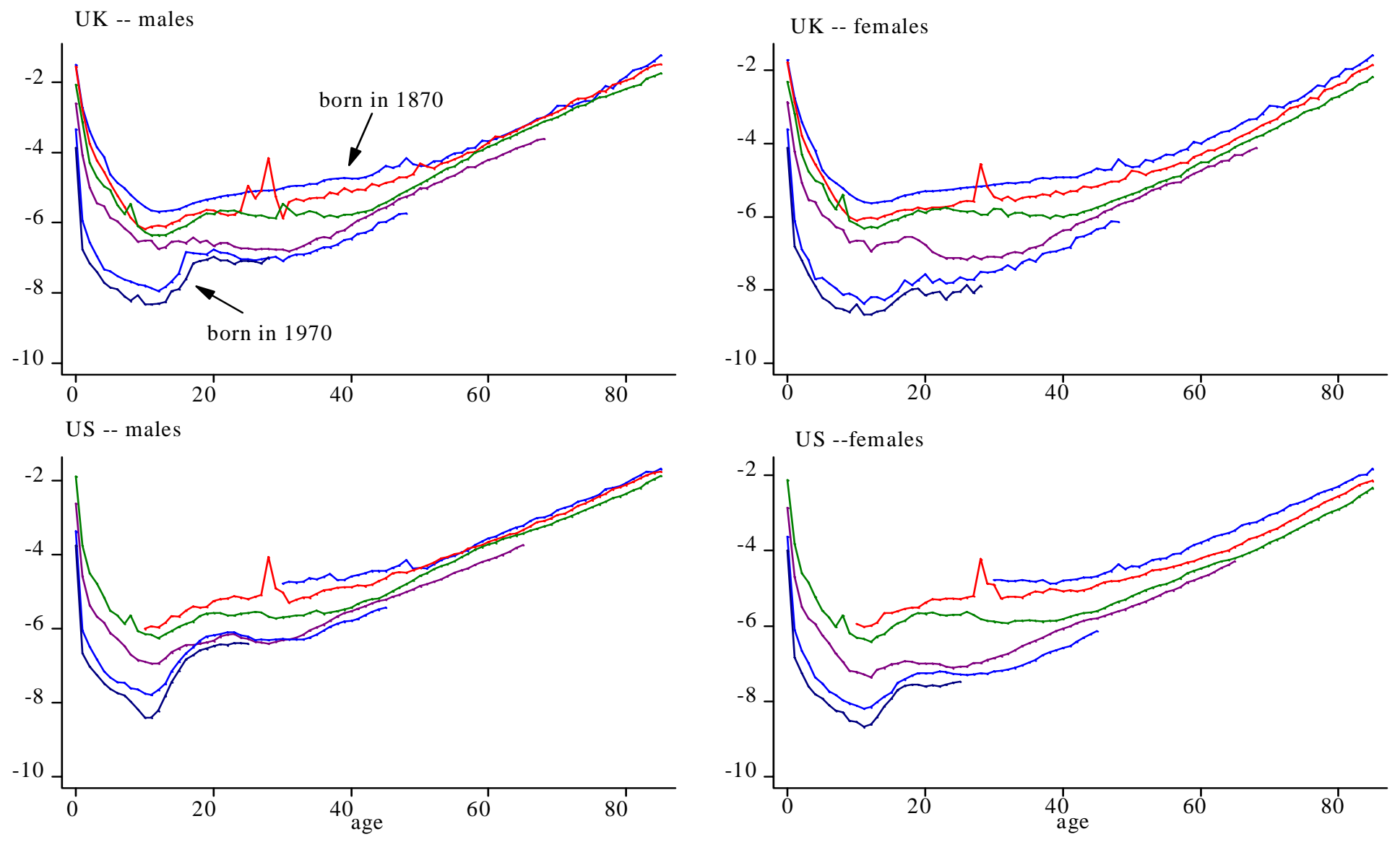

Figure 7: Log Odds of Mortality by Cohort, UK and US 

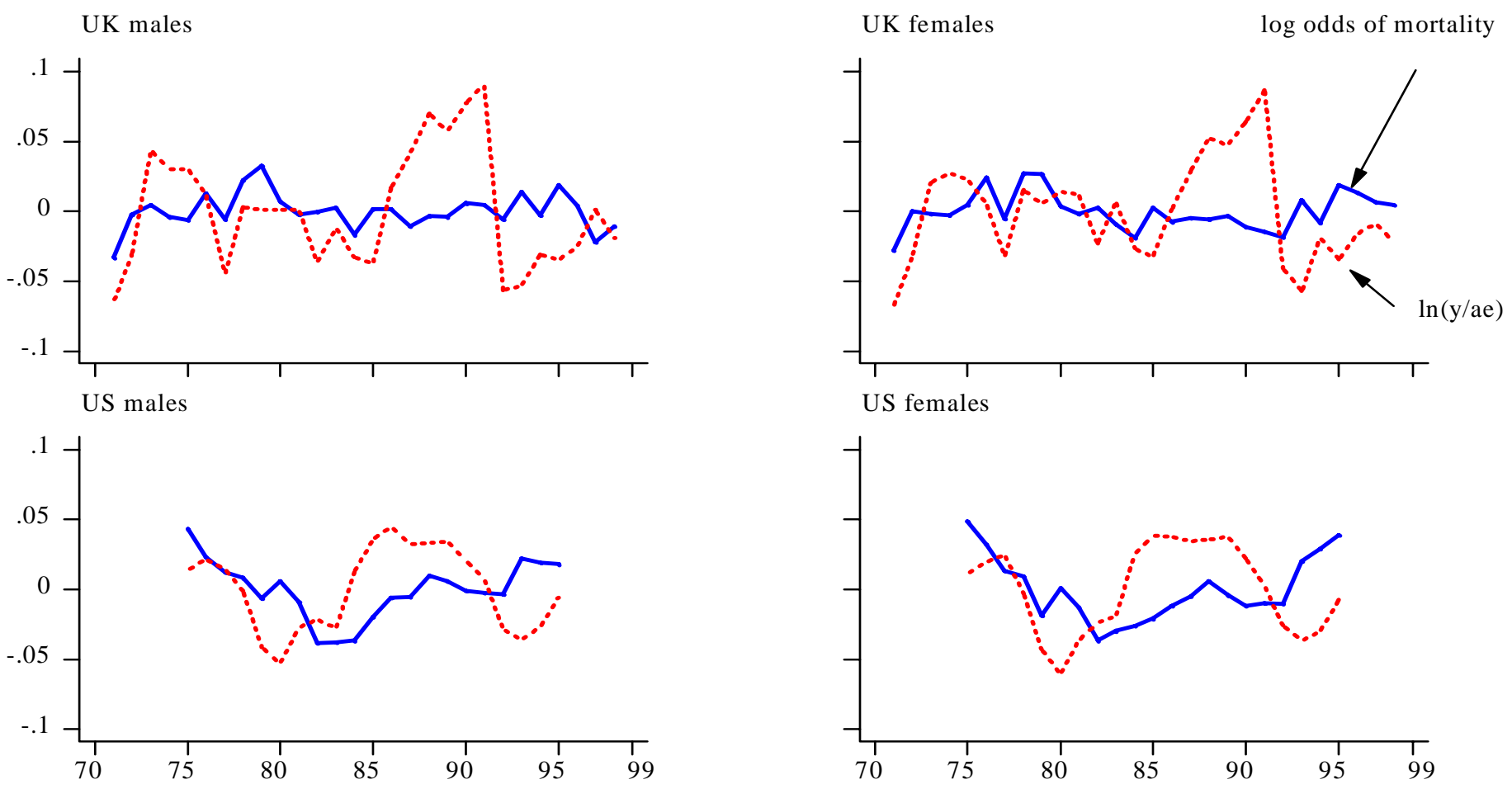

Note: graphed lines are of residuals, averaged over years, of a regression of the variable on a set of age dummies and a time trend.

Figure 8: Year-Averaged Residuals of Log Odds Mortality, UK and US 

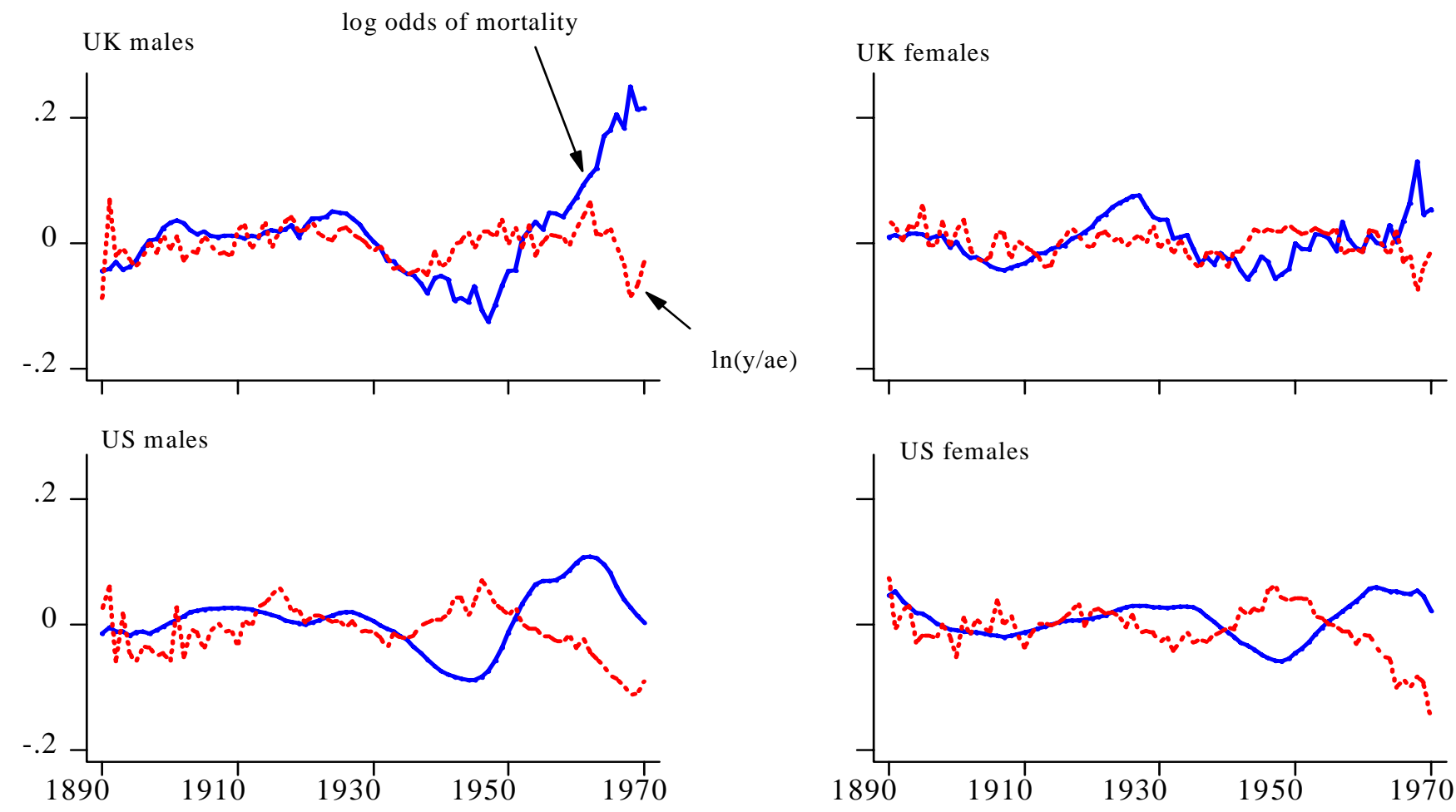

Year of birth

Note: graphed lines are of residuals, averaged over birth years, of a regression of the variable on a set of age dummies and a time trend.

Figure 9: Cohort-Averaged Residuals of Log Odds Mortality, UK and US 

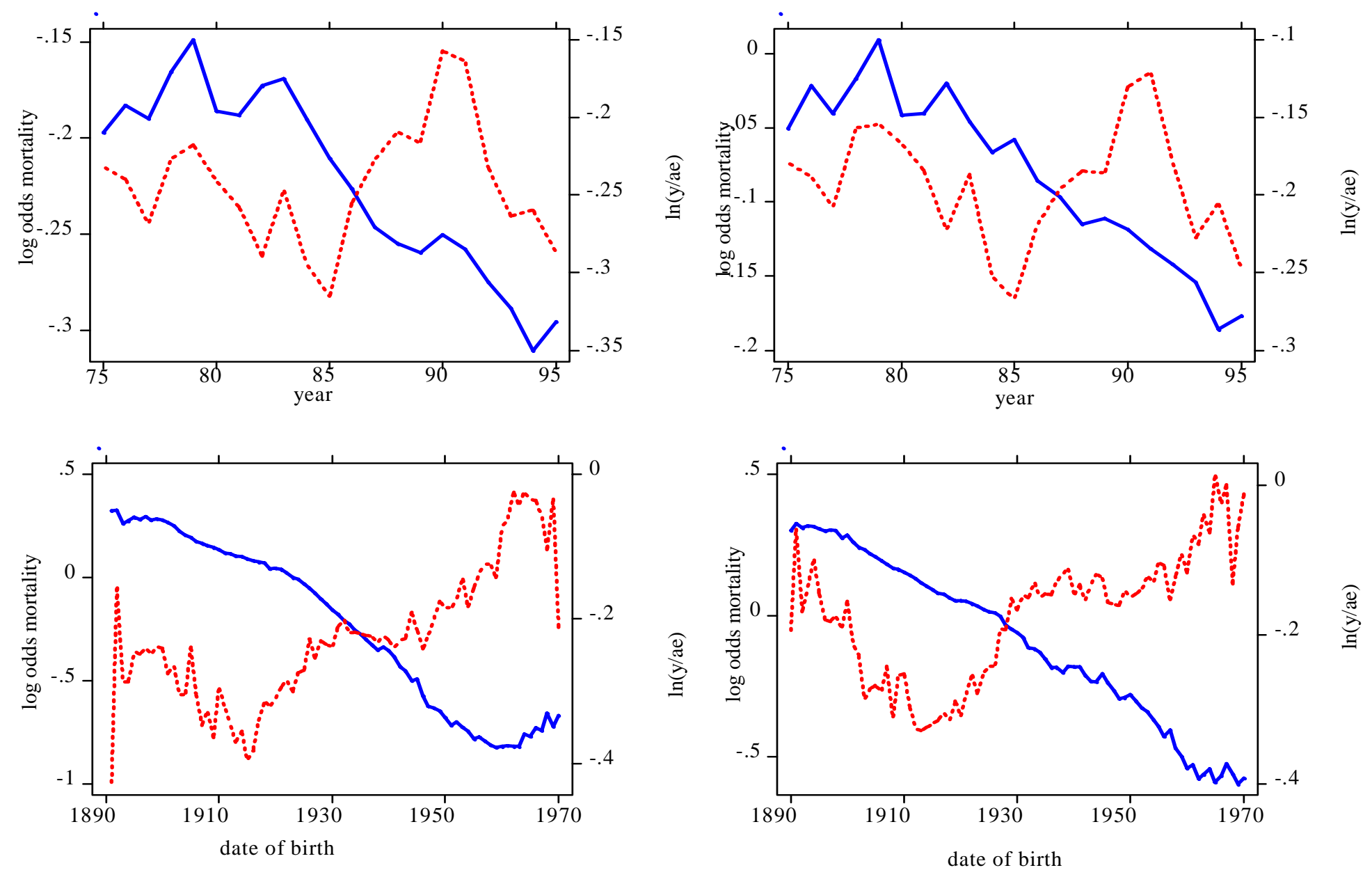

UK - US $\ln (\mathrm{y} / \mathrm{ae})$, averaged by year or birth year

UK-US log odds mortality, averaged by year or birth year

Figure 10: UK-US Differences in Mortality and Income 
Table 1: Log odds of dying as a function of income, by age group. Coefficients on mean $\ln ($ income/adult equivalent), $t$-statistics in parentheses.

\begin{tabular}{|c|c|c|c|c|c|c|c|c|c|c|c|c|}
\hline \multirow[b]{4}{*}{$\begin{array}{l}\text { All ages } \\
\text { ages } 25-39 \\
\text { ages } 40-54 \\
\text { ages } 55-69 \\
\text { ages } 70-85\end{array}$} & \multicolumn{6}{|c|}{ United States, 1975-1995 } & \multicolumn{6}{|c|}{ United Kingdom, 1971-1998 } \\
\hline & \multicolumn{2}{|c|}{$\begin{array}{l}\text { no time trend } \\
\text { (1) }\end{array}$} & \multicolumn{2}{|c|}{$\begin{array}{l}\text { time trend } \\
\text { (2) }\end{array}$} & \multicolumn{2}{|c|}{$\begin{array}{c}\text { trend }+ \text { trend/age } \\
\text { interaction } \\
\text { (3) }\end{array}$} & \multicolumn{2}{|c|}{$\begin{array}{l}\text { no time trend } \\
\text { (4) }\end{array}$} & \multicolumn{2}{|c|}{$\begin{array}{l}\text { time trend } \\
\text { (5) }\end{array}$} & \multicolumn{2}{|c|}{$\begin{array}{c}\text { trend }+ \text { trend/age } \\
\text { interaction } \\
(6)\end{array}$} \\
\hline & \multicolumn{12}{|c|}{ Males } \\
\hline & $\begin{array}{r}-0.559 \\
0.452 \\
-0.770 \\
-0.941 \\
-0.430\end{array}$ & $\begin{array}{c}(24.14) \\
(5.05) \\
(17.80) \\
(19.37) \\
(19.02)\end{array}$ & $\begin{array}{r}-0.281 \\
0.168 \\
-0.261 \\
0.107 \\
0.035\end{array}$ & $\begin{array}{l}(8.81) \\
(1.79) \\
(3.85) \\
(5.92) \\
(1.67)\end{array}$ & $\begin{array}{r}-0.079 \\
-0.075 \\
-0.229 \\
0.048 \\
0.057\end{array}$ & $\begin{array}{l}(2.48) \\
(0.83) \\
(4.43) \\
(3.08) \\
(4.18)\end{array}$ & $\begin{array}{l}-0.642 \\
-0.171 \\
-0.979 \\
-0.914 \\
-0.609\end{array}$ & $\begin{array}{c}(34.74) \\
(7.64) \\
(26.15) \\
(19.47) \\
(22.73)\end{array}$ & $\begin{array}{r}0.085 \\
-0.048 \\
0.030 \\
0.060 \\
0.002\end{array}$ & $\begin{array}{l}(4.00) \\
(1.07) \\
(0.86) \\
(2.66) \\
(0.12)\end{array}$ & $\begin{array}{r}0.072 \\
-0.005 \\
-0.051 \\
-0.009 \\
0.019\end{array}$ & $\begin{array}{l}(3.84) \\
(0.12) \\
(1.86) \\
(0.37) \\
(1.39)\end{array}$ \\
\hline & \multicolumn{12}{|c|}{ Females } \\
\hline $\begin{array}{l}\text { All ages } \\
\text { ages } 25-39 \\
\text { ages } 40-54 \\
\text { ages } 55-69 \\
\text { ages } 70-85\end{array}$ & $\begin{array}{l}-0.528 \\
-0.362 \\
-0.850 \\
-0.322 \\
-0.370\end{array}$ & $\begin{array}{c}(27.44) \\
(6.08) \\
(23.50) \\
(10.79) \\
(14.61)\end{array}$ & $\begin{array}{r}-0.125 \\
-0.174 \\
-0.022 \\
0.207 \\
0.059\end{array}$ & $\begin{array}{l}(5.35) \\
(2.65) \\
(0.50) \\
(9.26) \\
(2.84)\end{array}$ & $\begin{array}{r}-0.130 \\
-0.197 \\
-0.010 \\
0.117 \\
0.036\end{array}$ & $\begin{array}{l}(5.49) \\
(2.49) \\
(0.22) \\
(7.55) \\
(1.93)\end{array}$ & $\begin{array}{l}-0.774 \\
-0.691 \\
-1.039 \\
-0.671 \\
-0.686\end{array}$ & $\begin{array}{l}(44.53) \\
(19.89) \\
(27.86) \\
(21.46) \\
(21.42)\end{array}$ & $\begin{array}{r}0.019 \\
-0.035 \\
-0.011 \\
0.117 \\
0.033\end{array}$ & $\begin{array}{l}(1.01) \\
(0.71) \\
(0.34) \\
(3.62) \\
(1.89)\end{array}$ & $\begin{array}{r}0.023 \\
-0.032 \\
-0.026 \\
0.010 \\
-0.004\end{array}$ & $\begin{array}{l}(1.24) \\
(0.64) \\
(0.77) \\
(0.33) \\
(0.26)\end{array}$ \\
\hline
\end{tabular}

Notes: Each regression includes the mean of the logarithm of household income per adult equivalent (mean $\ln (y / a e))$ and a set of age dummies. The regressions are estimated for the full sample and for four different age groups. Each cell in the table reports a coefficient on the mean of log of income per adult equivalent from a single regression. 
Table 2: Log odds of dying as a function of income, education, and smoking. Trend included. $\mathrm{t}-$ statistics in parentheses.

\begin{tabular}{|c|c|c|c|c|c|c|}
\hline & US & UK & UK & US & UK & UK \\
\hline & \multicolumn{3}{|c|}{ all males } & \multicolumn{3}{|c|}{ all females } \\
\hline \multirow{4}{*}{$\begin{array}{l}\text { mean } \ln (y / a e) \\
\text { means years of schooling }\end{array}$} & $\begin{array}{l}0.093 \\
(2.91)\end{array}$ & $\begin{array}{l}0.057 \\
(2.36)\end{array}$ & $\begin{array}{l}0.071 \\
(2.97)\end{array}$ & $\begin{array}{c}-0.012 \\
(0.47)\end{array}$ & $\begin{array}{l}0.013 \\
(0.67)\end{array}$ & $\begin{array}{l}0.019 \\
(0.98)\end{array}$ \\
\hline & $\begin{array}{c}-0.115 \\
(22.0)\end{array}$ & -0.020 & $\begin{array}{c}-0.018 \\
(2.74)\end{array}$ & $\begin{array}{r}-0.065 \\
(106)\end{array}$ & $\begin{array}{c}-0.022 \\
(4.08)\end{array}$ & $\begin{array}{r}-0.017 \\
(3.05)\end{array}$ \\
\hline & & & $\begin{array}{l}0.203 \\
(5.55)\end{array}$ & & & $\begin{array}{l}0.154 \\
(4.92)\end{array}$ \\
\hline & \multicolumn{3}{|c|}{ males aged $35-59$} & \multicolumn{3}{|c|}{ females aged $35-59$} \\
\hline mean $\ln (y / a e)$ & $\begin{array}{l}0.201 \\
(3.49)\end{array}$ & $\begin{array}{l}0.070 \\
(1.83)\end{array}$ & $\begin{array}{l}0.079 \\
(2.03)\end{array}$ & $\begin{array}{l}0.001 \\
(0.02)\end{array}$ & $\begin{array}{c}-0.022 \\
(0.71)\end{array}$ & $\begin{array}{c}-0.015 \\
(.049)\end{array}$ \\
\hline means years of schooling & -0.260 & -0.029 & -0.027 & -0.191 & 0.008 & 0.012 \\
\hline \multirow[t]{2}{*}{ fraction smoke } & & & $\begin{array}{l}0.135 \\
(2.06)\end{array}$ & & & $\begin{array}{l}0.146 \\
(2.86)\end{array}$ \\
\hline & \multicolumn{3}{|c|}{ males aged $60-85$} & \multicolumn{3}{|c|}{ females aged $60-85$} \\
\hline mean $\ln (y / a e)$ & $\begin{array}{l}0.095 \\
(5.00)\end{array}$ & $\begin{array}{l}0.035 \\
(2.46)\end{array}$ & $\begin{array}{l}0.034 \\
(2.37)\end{array}$ & $\begin{array}{l}0.121 \\
(7.19)\end{array}$ & $\begin{array}{l}0.043 \\
(2.28)\end{array}$ & $\begin{array}{l}0.052 \\
(2.81)\end{array}$ \\
\hline mean years of schooling & $\begin{array}{l}0.002 \\
(0.52)\end{array}$ & $\begin{array}{c}-0.018 \\
(4.51)\end{array}$ & $\begin{array}{c}-0.018 \\
(4.55)\end{array}$ & $\begin{array}{c}-0.022 \\
(4.84)\end{array}$ & $\begin{array}{c}-0.031 \\
(5.98)\end{array}$ & $\begin{array}{c}-0.030 \\
(5.95)\end{array}$ \\
\hline fraction smoke & & & $\begin{array}{c}-0.013 \\
(0.65)\end{array}$ & & & $\begin{array}{l}0.128 \\
(4.68)\end{array}$ \\
\hline
\end{tabular}

Notes: Each regression includes a set of age dummies and a time trend. The regressions are estimated for the full sample, and for subsets of cohorts in different age groups. The data for the US are for 1975-1995, and for the UK are for 1978-1998. 
Table 3: Log odds of dying as a function of income, education, and smoking. Trend included. tstatistics in parentheses.

\begin{tabular}{|c|c|c|c|c|c|c|c|c|}
\hline & US & UK & UK & UK & US & UK & UK & UK \\
\hline & \multicolumn{4}{|c|}{ all males } & \multicolumn{4}{|c|}{ all females } \\
\hline mean $\ln (y / a e)$ & $\begin{array}{c}-0.279 \\
(8.74)\end{array}$ & $\begin{array}{c}0.040 \\
(1.65)\end{array}$ & $\begin{array}{l}0.069 \\
(2.81)\end{array}$ & $\begin{array}{l}0.086 \\
(2.99)\end{array}$ & $\begin{array}{c}-0.125 \\
(5.39)\end{array}$ & $\begin{array}{l}0.004 \\
(0.21)\end{array}$ & $\begin{array}{l}0.025 \\
(1.23)\end{array}$ & $\begin{array}{c}0.016 \\
(0.69)\end{array}$ \\
\hline gini $\ln (y / a e)$ & $\begin{array}{r}-0.159 \\
(164)\end{array}$ & $\begin{array}{r}-0.020 \\
(0.40)\end{array}$ & $\begin{array}{l}0.028 \\
(057)\end{array}$ & $\begin{array}{l}0.026 \\
(045)\end{array}$ & $\begin{array}{r}-0.116 \\
(1.54)\end{array}$ & $\begin{array}{r}-0.078 \\
(2.08)\end{array}$ & -0.053 & $\begin{array}{r}-0.017 \\
036\end{array}$ \\
\hline mean years of schooling & & & $\begin{array}{c}-0.019 \\
(2.80)\end{array}$ & $\begin{array}{c}-0.020 \\
(2.67)\end{array}$ & & & $\begin{array}{r}-0.015 \\
(2.72)\end{array}$ & $\begin{array}{c}-0.021 \\
(3.22)\end{array}$ \\
\hline fraction smoke & & & $\begin{array}{l}0.204 \\
(5.57)\end{array}$ & $\begin{array}{l}0.250 \\
(5.92)\end{array}$ & & & $\begin{array}{l}0.154 \\
(4.94)\end{array}$ & $\begin{array}{l}0.147 \\
(4.11)\end{array}$ \\
\hline \multirow[t]{2}{*}{ fraction unemployed } & & & & $\begin{array}{l}0.047 \\
(0.75)\end{array}$ & & & & $\begin{array}{c}-0.086 \\
(2.11)\end{array}$ \\
\hline & \multicolumn{4}{|c|}{ males aged $35-59$} & \multicolumn{4}{|c|}{ females aged 35-59 } \\
\hline mean $\ln (y / a e)$ & $\begin{array}{c}-0.435 \\
(6.49)\end{array}$ & $\begin{array}{l}0.051 \\
(1.33)\end{array}$ & $\begin{array}{l}0.078 \\
(2.02)\end{array}$ & $\begin{array}{c}0.069 \\
(1.63)\end{array}$ & $\begin{array}{c}-0.255 \\
(5.93)\end{array}$ & $\begin{array}{c}-0.016 \\
(0.54)\end{array}$ & $\begin{array}{r}-0.015 \\
(0.48)\end{array}$ & $\begin{array}{c}-0.022 \\
(0.71)\end{array}$ \\
\hline $\operatorname{gini}(y / a e)$ & $\begin{array}{c}-1.367 \\
(5.92)\end{array}$ & $\begin{array}{c}-0.022 \\
(0.24)\end{array}$ & $\begin{array}{l}0.011 \\
(0.13)\end{array}$ & $\begin{array}{l}0.026 \\
(0.28)\end{array}$ & $\begin{array}{c}-0.234 \\
(1.46)\end{array}$ & $\begin{array}{l}0.001 \\
(0.02)\end{array}$ & $\begin{array}{c}-0.007 \\
(0.11)\end{array}$ & $\begin{array}{c}0.006 \\
(0.08)\end{array}$ \\
\hline mean years of schooling & & & $\begin{array}{r}-0.027 \\
(2.34)\end{array}$ & $\begin{array}{c}-0.028 \\
(2.39)\end{array}$ & & & $\begin{array}{l}0.012 \\
(1.26)\end{array}$ & $\begin{array}{c}0.012 \\
(1.16)\end{array}$ \\
\hline fraction smoke & & & $\begin{array}{l}0.135 \\
(2.06)\end{array}$ & $\begin{array}{l}0.136 \\
(2.07)\end{array}$ & & & $\begin{array}{l}0.146 \\
(2.85)\end{array}$ & $\begin{array}{c}0.148 \\
(2.90)\end{array}$ \\
\hline \multirow[t]{2}{*}{ fraction unemployed } & & & & $\begin{array}{c}-0.057 \\
(0.55)\end{array}$ & & & & $\begin{array}{c}-0.101 \\
(1.16)\end{array}$ \\
\hline & \multicolumn{4}{|c|}{ males aged $60-85$} & \multicolumn{4}{|c|}{ females aged $60-85$} \\
\hline mean $\ln (y / a e)$ & $\begin{array}{l}0.115 \\
(6.33)\end{array}$ & $\begin{array}{l}0.015 \\
(1.02)\end{array}$ & $\begin{array}{l}0.033 \\
(2.13)\end{array}$ & $\begin{array}{l}0.078 \\
(4.35)\end{array}$ & $\begin{array}{l}0.102 \\
(6.04)\end{array}$ & $\begin{array}{l}0.008 \\
(0.41)\end{array}$ & $\begin{array}{l}0.053 \\
(2.67)\end{array}$ & $\begin{array}{l}0.055 \\
(2.11)\end{array}$ \\
\hline $\operatorname{gini}(y / a e)$ & $\begin{array}{c}-0.175 \\
(3.80)\end{array}$ & $\begin{array}{c}-0.016 \\
(0.59)\end{array}$ & $\begin{array}{l}0.009 \\
(0.33)\end{array}$ & $\begin{array}{l}0.015 \\
(0.47)\end{array}$ & $\begin{array}{c}-0.032 \\
(0.66)\end{array}$ & $\begin{array}{c}-0.010 \\
(0.30)\end{array}$ & $\begin{array}{c}-0.006 \\
(0.19)\end{array}$ & $\begin{array}{l}0.093 \\
(2.26)\end{array}$ \\
\hline mean years of schooling & & & $\begin{array}{c}-0.018 \\
(4.52)\end{array}$ & $\begin{array}{c}-0.027 \\
(5.71)\end{array}$ & & & $\begin{array}{c}-0.030 \\
(5.91)\end{array}$ & $\begin{array}{r}-0.055 \\
(8.80)\end{array}$ \\
\hline fraction smoke & & & $\begin{array}{c}-0.013 \\
(0.63)\end{array}$ & $\begin{array}{c}-0.018 \\
(0.76)\end{array}$ & & & $\begin{array}{l}0.128 \\
(4.67)\end{array}$ & $\begin{array}{l}0.118 \\
(3.64)\end{array}$ \\
\hline fraction unemployed & & & & $\begin{array}{l}0.083 \\
(2.55)\end{array}$ & & & & $\begin{array}{c}-0.021 \\
(0.80)\end{array}$ \\
\hline
\end{tabular}

Notes: Each regression includes a set of age dummies and a time trend. The regressions are estimated for the full sample, and for subsets of cohorts in different age groups. The data for the US are for 1975-1995, and for the UK are for 1978-1998. 
Table 4: Pooled US and UK regressions, log odds of mortality, 1975-1995. Each cell shows a coefficient for $\ln (y / a e)$ from a single regression (t-statistics in parentheses.)

\begin{tabular}{|c|c|c|c|c|c|c|}
\hline & US & UK & US & UK & pooled US\&UK & pooled US\&UK \\
\hline \multicolumn{7}{|c|}{ Males } \\
\hline $\ln (y / a e)$ & $\begin{array}{c}-0.559 \\
(24.2)\end{array}$ & $\begin{array}{c}-0.462 \\
(16.7)\end{array}$ & $\begin{array}{c}-0.375 \\
(11.0)\end{array}$ & $\begin{array}{c}0.099 \\
(3.9)\end{array}$ & $\begin{array}{c}-0.874 \\
(27.0)\end{array}$ & $\begin{array}{c}-0.885 \\
(20.5)\end{array}$ \\
\hline \multicolumn{7}{|c|}{ Females } \\
\hline $\ln (y / a e)$ & $\begin{array}{c}-0.528 \\
(27.4)\end{array}$ & $\begin{array}{c}-0.602 \\
(20.0)\end{array}$ & $\begin{array}{c}-0.186 \\
(7.7)\end{array}$ & $\begin{array}{c}0.028 \\
(1.2)\end{array}$ & $\begin{array}{c}-0.813 \\
(32.7)\end{array}$ & $\begin{array}{c}-0.636 \\
(20.6)\end{array}$ \\
\hline age dummies? & yes & yes & yes & yes & yes & yes \\
\hline year dummies? & no & no & yes & yes & no & yes \\
\hline UK dummy? & no & no & no & no & yes & yes \\
\hline \multicolumn{7}{|c|}{ F-tests on restrictions of equality of coefficients across countries in pooled regression: } \\
\hline \multicolumn{6}{|c|}{ Men: Age effects for UK=Age effects for US $-\mathrm{F}(60,2379)$} & 161.84 \\
\hline \multicolumn{6}{|c|}{ Men: Year effects for UK=Year effects for US - F(20,2379) } & 22.51 \\
\hline \multicolumn{6}{|c|}{ Women: Age effects for UK=Age effects for US - F(60,2397) } & 138.33 \\
\hline \multicolumn{6}{|c|}{ Women: Year effects for UK=Year effects for US $-F(20,2397)$} & 33.23 \\
\hline
\end{tabular}

